FLÁVIA FAIRBANKS LIMA DE OLIVEIRA MARINO

\title{
Avaliação das dosagens das interleucinas 12 e 18 no sangue e no fluido peritoneal de pacientes com endometriose pélvica
}

\author{
Dissertação apresentada à Faculdade de Medicina \\ da \\ Universidade de São Paulo para obtenção do título de \\ Mestre em Ciências
}

Área de concentração: Obstetrícia e Ginecologia

Orientador: Prof. Dr. Mauricio Simões Abrão

São Paulo

2006 
Dados Internacionais de Catalogação na Publicação (CIP)

Preparada pela Biblioteca da

Faculdade de Medicina da Universidade de Sào Paulo

Creprodução autorizada pelo autor

Marino, Flávia Fairbanks Lima de Oliveira

Avaliação das dosagens das interleucinas 12 e 18 no sangue e no fluido

peritoneal de pacientes com endometriose pélvica / Flávia Fairbanks Lima de Oliveira Marino. -- São Paulo, 2006.

Dissertação(mestrado)--Faculdade de Medicina da Universidade de São Paulo. Departamento de Obstetrícia e Ginecologia.

Área de concentração: Obstetrícia e Ginecologia.

Orientador: Maurício Simōes Abrão.

Descritores: 1.Endometriose/imunologia 2. Interleucina 12 3.Interleucina 18 4.Ciclo menstrual 5.Estadiamento de neoplasias 6. Histologia/classificação 


\section{Dedico este trabalho}

Ao meu pai, pelo eterno incentivo, apoio e amizade.

À minha mãe, pelo amor e carinho que sempre me dedicou.

À Letícia, minha filha querida, pela compreensão.

Ao Miguel, pelo companheirismo destes anos juntos. 


\section{AGRADECIMENTOS}

Ao Prof. Dr. Mauricio Simões Abrão pela excelente dedicação e orientação;

Aos colegas Sergio Podgaec e João Antonio Dias Jr., pelas contribuições, sugestões e análises;

Ao meu marido, Miguel, pelo auxílio e contribuições;

Ao meu irmão, Rafael, pelo auxílio na elaboração do trabalho;

À minha sogra, Maria Tereza, pela correção em Língua Portuguesa;

À Profa. Ângela Maggio da Fonseca, pelo apoio e contribuições;

Ao Prof. Edmund Chada Baracat, pelas sugestões e oportunidade de realizar esse trabalho;

Ao Prof. Dr. Luiz Vicente Rizzo pelas sugestões e contribuições;

Ao Dr. Ricardo de Oliveira pelas sugestões e contribuições;

À Srta. Júlia Fukushima, pela análise estatística;

À Srta. Cláudia, secretária da Pós-Graduação da Ginecologia do Hospital das Clínicas, pelo auxílio;

À Srta. Ana Cristina, pelo auxílio com o material de laboratório;

Ao RDO Diagnósticos Médicos pelo uso do laboratório;

A todos os colegas do Setor da Endometriose do Hospital das Clínicas da FMUSP, pelo auxílio com a coleta do material;

À FAPESP pelo apoio financeiro;

Às pacientes pela possibilidade de realização deste trabalho. 


\section{SUMÁRIO}

Lista de abreviaturas

Lista de tabelas

Resumo

Summary

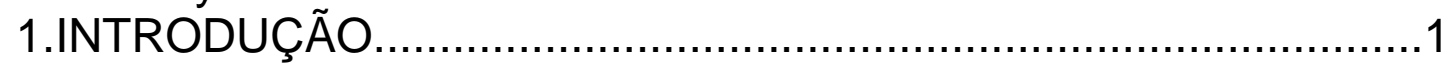

$1.1 \mathrm{~A}$ imunologia e a endometriose................................................

1.2 Papel das citocinas na etiopatogenia da endometriose.............10

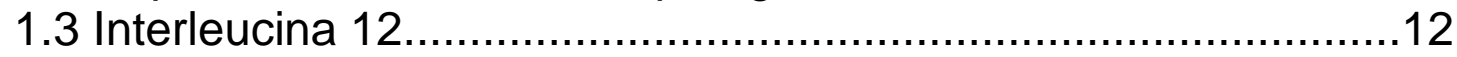

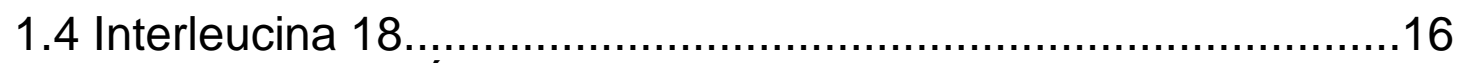

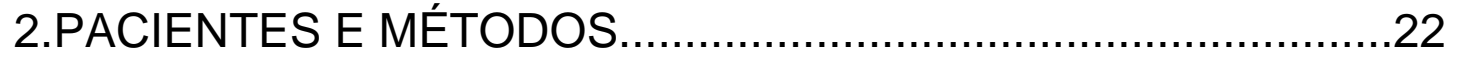

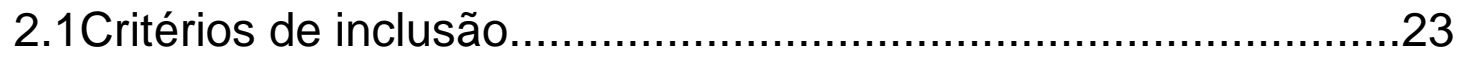

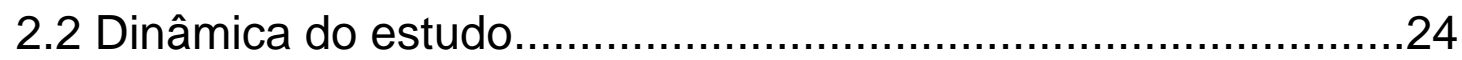

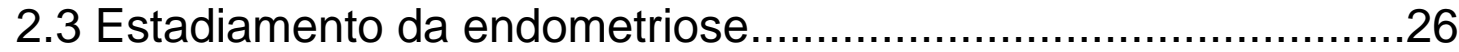

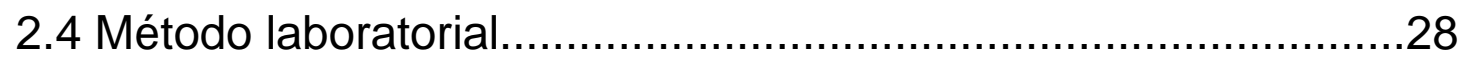

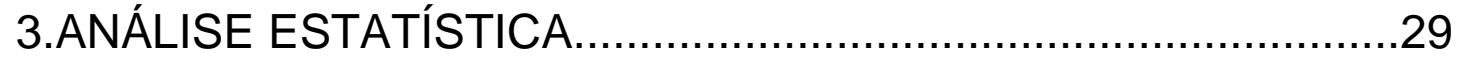

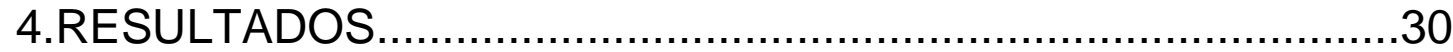

5.DISCUSSÃO

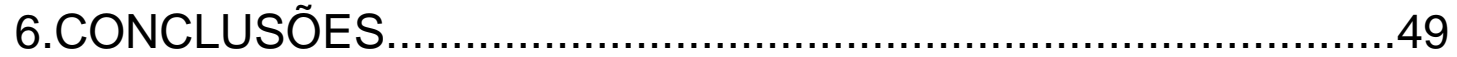

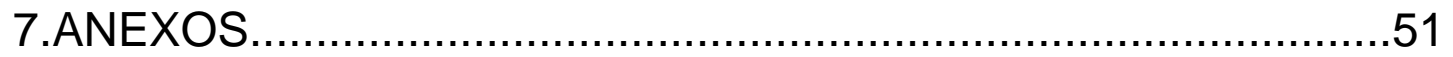

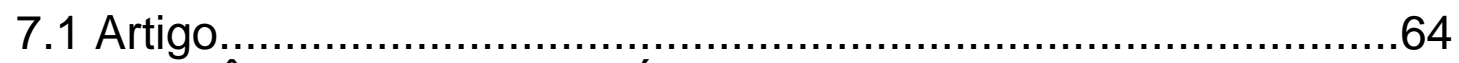

8.REFERÊNCIAS BIBLIOGRÁFICAS ......................................77 
Marino FFLO. Avaliação das dosagens das interleucinas 12 e 18 no sangue e no fluido peritoneal de pacientes com endometriose pélvica [dissertação]. São Paulo: Faculdade de Medicina da Universidade de São Paulo; 2006.

O objetivo deste trabalho foi analisar o comportamento das interleucinas 12 (IL12) e 18 (IL-18) em pacientes com endometriose pélvica comparando-as a pacientes de um grupo controle com sintomas sugestivos de endometriose e ausência comprovada da doença. Avaliamos, também, as dosagens das referidas interleucinas em relação à fase do ciclo menstrual, quadro clínico, local da doença, estadiamento e classificação histológica. PACIENTES E MÉTODOS: Foram avaliadas 105 pacientes entre 18 e 40 anos submetidas à videolaparoscopia, ; divididas em 2 grupos: 72 pacientes com endometriose e 33 controles. Colheu-se sangue periférico e fluido peritoneal no intra-operatório e procedeu-se a avaliação das interleucinas, relacionando-se as dosagens entre o grupo controle e o grupo com endometriose e também entre os parâmetros já mencionados. Dividimos as pacientes segundo a fase do ciclo menstrual, o quadro clínico, o local de maior gravidade da doença (peritoneal, ovariana ou profunda), o estadiamento e a classificação histológica. As dosagens das interleucinas foram feitas através do método de ELISA e a análise estatística pela aplicação dos testes Kruskal-Wallis e Dunn. RESULTADOS: A média das dosagens da IL-12 no fluido peritoneal foi significativamente maior nas pacientes com endometriose $(82,37+/$ - 16,61 $\mathrm{pg} / \mathrm{mL})$ que no grupo controle $(29,20+/-10,21 \mathrm{pg} / \mathrm{mL}), p<0,001$. Não houve diferenças significativas na comparação das dosagens séricas de IL-12 entre pacientes e grupo controle. As médias das dosagens da IL-12 no sangue de pacientes com endometriose avançada foi significativamente mais elevada $(196,74+/-33,71 \mathrm{pg} / \mathrm{mL})$ que aquela de pacientes com doença inicial $(82,04$ +/$16,63 \mathrm{pg} / \mathrm{mL}), p=0,007$. Não houve diferenças significativas entre as dosagens de IL-18 no sangue e no fluido peritoneal de pacientes e grupo 
controle, nem em relação à comparação entre doença inicial e doença avançada. As médias das dosagens de IL-12 no fluido peritoneal foram mais elevadas em pacientes com endometriose com dismenorréia severa/incapacitante $(82,21+/-20,54 \mathrm{pg} / \mathrm{mL} ; \mathrm{p}=0,02)$, dispareunia de profundidade $(101,62+/-29,25 \mathrm{pg} / \mathrm{mL} ; \mathrm{p}=0,02)$ e dor acíclica $(101,93+/-26,14$ $\mathrm{pg} / \mathrm{mL} ; \mathrm{p}=0,02)$. As médias das dosagens de IL-18 no sangue foram mais elevadas em pacientes com endometriose com dismenorréia severa/incapacitante $(77,59+/-16,50 \mathrm{pg} / \mathrm{mL} ; \mathrm{p}=0,01)$ e dispareunia de profundidade $(61,34+/-14,05 \mathrm{pg} / \mathrm{mL} ; p=0,03)$. Não houve diferenças significativas entre as dosagens de IL-12 e IL-18, no sangue ou no fluido peritoneal, de acordo com a localização da doença (peritônio, ovário ou doença profunda). Não houve diferenças significativas entre as dosagens de IL-12 e IL18, no sangue ou no fluido peritoneal, de acordo com a classificação histológica da doença (estromal, bem-diferenciada, padrão misto de diferenciação e indiferenciada). CONCLUSÕES: A interleucina 12 esteve aumentada no fluido peritoneal de pacientes com endometriose, e no sangue nos estádios avançados da doença. Não houve diferenças nas dosagens da interleucina 18 no sangue ou fluido peritoneal na endometriose em relação a mulheres sem a doença.

Descritores: endometriose/imunologia, interleucina 12, interleucina 18 , ciclo menstrual, local, estadiamento, histologia/classificação. 
Marino FFLO. Evaluation of the levels of interleukines 12 and 18 in blood and peritoneal fluid of patients with pelvic endometriosis [ dissertation ]. São Paulo: College of Medicine of the University of São Paulo; 2006.

The aim of this work was to evaluate the behavior of interleukines 12 (IL-12) and 18 (IL-18) in patients with pelvic endometriosis comparing them with a control group that presented suggestive symptoms of endometriosis and proven absence of the disease, evaluating, also, the levels of the interleukines in relation to the phase of menstrual cycle, clinical symptoms, primary location, disease stage and histological classification. PATIENTS AND METHODS: 105 patients aging from 18 to 40 years have been submitted to the laparoscopic surgery and classified in 2 groups: 72 patients with endometriosis and 33 controls. Peripheral blood and peritoneal fluid were extracted and interleukins were evaluated, correlating the levels between the control group and the group with endometriosis, and also between the parameters previously mentioned. Patients were grouped according to the phase of the menstrual cycle, clinical symptoms, primary location, disease stage and histological classification. Interleukin levels have been measured by ELISA. Statistical analysis was performed by the application of Kruskal-Wallis and Dunn tests. RESULTS: Average levels of IL-12 in the peritoneal fluid was significantly higher in patients with endometriosis $(82,37+/-16.61 \mathrm{pg} / \mathrm{mL})$ when compared to the control group $(29,20+/-10,21 \mathrm{pg} / \mathrm{mL}), \mathrm{p}<0,001$. No significant differences were found in the comparison of the serum levels of IL-12 between patients and control group.) Average levels of IL-12 in blood of patients with advanced endometriosis were significantly increased $(196,74+/-33.71 \mathrm{pg} / \mathrm{mL})$ when compared to patients with initial disease $(82,04+/-16,63 \mathrm{pg} / \mathrm{mL}), \mathrm{p}=0,007$. There were no significant differences between the levels of IL-18 in blood and in peritoneal fluid of patients and control group, nor between patients with initial disease and advanced disease. Average levels of IL-12 in peritoneal fluid were higher in patients with endometriosis with complaints of severe / incapacitating dysmenorrhea (82.21 
+/- 20,54 pg/mL; $p=0,02)$, deep dyspareunia $(101,62+/-29,25 \mathrm{pg} / \mathrm{mL} ; p=0,02)$ and acyclic pain $(101,93+/-26,14 \mathrm{pg} / \mathrm{mL} ; \mathrm{p}=0,02)$. Average levels of IL-18 in the blood were higher in patients with endometriosis and severe /incapacitating dysmenorrhea $(77,59+/-16,50 \mathrm{pg} / \mathrm{mL} ; \mathrm{p}=0,01)$ and deep dyspareunia $(61,34$ $+/-14,05 \mathrm{pg} / \mathrm{mL} ; p=0,03)$. There were no significant differences between the levels of IL-12 and IL-18, in blood or in peritoneal fluid, according to the primary location of the disease (peritoneal, ovarian or deep infiltrative disease). No significant differences were found between the levels of IL-12 and IL-18, in blood or peritoneal fluid, in accordance to the histological classification of the disease (estromal, well-differentiated, combined standard of differentiation and undifferentiated). CONCLUSIONS: Interleukin 12 wss increased in peritoneal fluid of patients with endometriosis, and in blood in advanced stages of the disease. There were no differences in the levels of interleukin 18 in blood or peritoneal fluid in endometriosis compared to women without the disease.

Desciptors: endometriosis/immunology; interleukin-12; interleukin-18; menstrual cycle; neoplasm staging; histology/classification. 
INTRODUÇÃO 


\section{Introdução}

Endometriose caracteriza-se pelo implante, crescimento e desenvolvimento de glândula e/ou estroma endometriais em localização extra-uterina (D'Hooghe et al., 2003).

Estima-se que $10 \%$ da população feminina na menacme apresentam essa doença (Missmer e Cramer,2003) e, quando são estudadas populações específicas de mulheres com dor pélvica, dismenorréia ou infertilidade, a prevalência varia de 6 a 58\% dos casos (Matorras et al.,1995; Izzo et al., 2000).

Os impactos econômico e social causados pela endometriose são significativos. Nos Estados Unidos da América, análises demostraram que um terço das internações hospitalares por causas ginecológicas foram devidas à endometriose (Dmowski et al., 1997). Outrossim, essas mulheres devem ser acompanhadas cuidadosamente do ponto de vista ginecológico ao longo de toda sua vida, pois podem apresentar maior risco de câncer de ovário, mama, pele, além de risco elevado de outras doenças imunológicas (Giudice e Kao, 2004). Estudos mais recentes defendem que o enfoque multidisciplinar é fundamental na abordagem da paciente com endometriose, priorizando, além de aspectos médicos, o acompanhamento psicológico das mesmas, pois têm risco elevado de síndromes depressivas, provavelmente devido às dores crônicas que apresentaram (Belaisch e Allart, 2006).

Do ponto de vista da etiopatogenia, Meyer, em 1919, descreveu a teoria da metaplasia celômica. Segundo essa teoria, células do epitélio celômico transformar-se-iam em células endometriais em localizações anômalas. Esse raciocínio explicava coerentemente a ocorrência da doença em sítios longínquos da pelve, como a pleura e os pulmões, e também a endometriose em homens; mais tarde também se atribuiu à metaplasia celômica a explicação da endometriose em mulheres sem menstruação retrógrada e nos endometriomas profundos do ovário (Witz, 2002). 
Em 1927, Sampson propôs a teoria da menstruação retrógrada, segundo a qual células endometriais com capacidade de proliferação e implantação refluiriam pelas tubas uterinas, pérvias no período menstrual, alojando-se, principalmente, na superfície dos ovários, no peritônio pélvico e no fundo-de-saco posterior. Essa teoria pôde ser comprovada por diversos estudos que permitiram a visualização do refluxo menstrual por via videolaparoscópica em mais de 90\% das mulheres (Koninckx et al., 1999), por obtenção de tecido endometrial viável no fluido peritoneal e ainda por outros estudos que conseguiram desenvolver experimentalmente a endometriose em modelos animais, transplantando endométrio humano (Wu e Ho, 2003).

Em tempos recentes, após a avaliação de que a menstruação retrógrada era um fenômeno quase universal entre as mulheres e de que somente parte delas desenvolvia endometriose, alguns autores cogitaram a existência de fatores imunológicos na etiopatogenia da doença (Nothnick, 2001). Pensou-se que, provavelmente, a alteração do mecanismo imunológico fosse restrita ao ambiente peritoneal, mas que pudesse envolver as duas facetas da resposta imune, a celular e a humoral. Assim, passou a vigorar o conceito de que a endometriose seria um processo inflamatório pélvico local com alterações nas funções das células imunológicas do ambiente peritoneal (Harada et al., 2001; Wu e Ho, 2003). A base fundamental do processo seria uma alteração da resposta imunológica ao tecido endometrial refluído pelas trompas, o que explicaria, assim, a origem e a manutenção da lesão endometrial, havendo fundamentalmente redução da capacidade de depuração dos debris menstruais da cavidade peritoneal (Lebovic et al., 2001).

Os estudos para avaliação das funções imunológicas em pacientes com endometriose são numerosos, oferecendo resultados promissores no sentido de um entendimento mais claro da doença (Berkkanoglu e Arici, 2003). 


\section{Conceitos básicos de imunologia}

O sistema imune do ser humano é complexo. Seus principais constituintes são as células, que têm funções diversas, sempre com um objetivo comum: destruir o antígeno responsável pela ativação inicial da resposta imunológica. Os principais grupos celulares envolvidos são os leucócitos, divididos em linfócitos, fagócitos e células auxiliares e outras células diversas teciduais, espalhadas nos diferentes sistemas do organismo (Roitt et al., 2003)

Ao iniciar sua participação na resposta imunológica, as células produzem e secretam diferentes substâncias responsáveis pela comunicação intercelular e pelo mecanismo final de destruição do antígeno, sendo elas, respectivamente, as citocinas e os anticorpos (Benjamini et al., 2002).

Dentre os tipos celulares acima mencionados as células fagocíticas, os linfócitos $T$ e $B$ têm papel de destaque. Os fagócitos reconhecem os antígenos e os interiorizam para processá-los no ambiente intracelular. São representados pelos monócitos sangüíneos, células de Kupffer no fígado, células sinoviais nas articulações e macrófagos teciduais. A função básica das células fagocíticas é processar os antígenos quebrando-os em pequenos fragmentos para posterior apresentação aos linfócitos T (Roitt et al., 2003).

Os linfócitos são as células responsáveis pelo reconhecimento específico dos antígenos. Há dois tipos de linfócitos: T e B, com atividades distintas na resposta imune. De acordo com o linfócito envolvido e com a função por ele desempenhada, modula-se o tipo de resposta imune, celular (relacionada com o linfócito T) ou humoral (relacionada com o linfócito B) (Roitt et al, 2003).

Os linfócitos T, por sua vez, são subdivididos em três grupos: T auxiliares tipo 1 ou Th1, T auxiliares tipo 2 ou Th2 e T citotóxicos. Os linfócitos Th1 interagem diretamente com os fagócitos, reconhecendo os 
antígenos por eles apresentados e desencadeando mecanismos celulares de destruição antigênica. Os linfócitos Th2, por outro lado, interagem com os linfócitos B, transformando-os em plasmócitos, após reconhecer os antígenos por eles apresentados, determinando a secreção de anticorpos específicos contra esses antígenos. Já os linfócitos $\mathrm{T}$ citotóxicos reconhecem e destroem células infectadas por parasitas intracelulares, como, por exemplo, os vírus (Roitt et al., 2003).

O reconhecimento dos antígenos, seja pelas células $T$ ou $B$, exige a participação de moléculas especiais localizadas na superfície celular onde esses antígenos se fixam, chamadas de moléculas do complexo principal de histocompatibilidade (CPH). Ambos os tipos de linfócitos possuem receptores específicos, que são atraídos pelo $\mathrm{CPH}$ para iniciar o processo de reconhecimento antigênico. Há duas classes de moléculas do $\mathrm{CPH}$, (1 e 2), sendo as de classe 1 responsáveis pelo reconhecimento de antígenos endógenos intracelulares - tendo relação direta com as células T citotóxicas - e as de classe 2 responsáveis pelo reconhecimento de antígenos exógenos, portanto diretamente envolvidas com a função das células $T$ auxiliares (Benjamini et al, 2002).

Após todas as etapas acima descritas terem sido cumpridas, e estabelecido o reconhecimento adequado dos antígenos, os linfócitos ativados iniciam a produção de mediadores solúveis denominados citocinas, responsáveis pela comunicação entre as células do sistema imune, controlando a resposta imune em diversos níveis, como inflamação, defesa infecciosa e proliferação dos clones celulares T e B (Ulukus e Arici, 2005).

A estrutura molecular das citocinas aproxima-se daquela de pequenas proteínas com peso molecular inferior a $80 \mathrm{KDa}$. Normalmente, as citocinas têm ação autócrina ( sobre as próprias células que as produziram) ou parácrina ( sobre células próximas às de sua produção), sendo consideradas "mensageiras" solúveis (Barcz et al., 2000).

O termo citocina engloba várias substâncias com funções diversas e altamente específicas, como as interleucinas, interferons, fatores de 
necrose tumoral, fatores de crescimento, fatores estimuladores de colônias e quimioscinas. Há mais de duzentos tipos de citocinas isoladas em laboratório que, para facilidade de estudo e pesquisa, são agrupadas em famílias de acordo com a semelhança de estrutura molecular (D'Hooghe et al., 2001).

O padrão local de secreção das citocinas é responsável pela seleção dos mecanismos efetores dos linfócitos nas respostas polarizadas Th1 e Th2. Na resposta Th1, estão envolvidos, fundamentalmente, o interferon gama, o fator de necrose tumoral beta e a interleucina 2, que promovem a fixação dos fatores do complemento, a ativação dos macrófagos e a citotoxicidade celular. Já na resposta Th2, as principais citocinas envolvidas são as interleucinas 4, 5 e 10, que determinam o padrão de resposta humoral dependente dos anticorpos. Assim, de um modo simplificado, assume-se que a resposta imune Th1 esteja mais associada às reações inflamatórias mediadas por células, enquanto a resposta Th2, às respostas mediadas por anticorpos e alérgicas (Abbas et al., 1996).

Para que haja uma definição por um ou outro tipo de resposta - Th1 ou Th2 -, as células Th primordiais indiferenciadas sofrem a influência de alguns fatores, como o sítio de apresentação do antígeno, os tipos de moléculas co-estimuladoras, as afinidades com as moléculas $\mathrm{CPH}$ classe 2 (afinidade elevada favorece resposta Th1 e baixa Th2) e, principalmente, o perfil e o equilíbrio das citocinas provocadas pelo antígeno (Abbas et al, 1996).

Merece destaque em todo esse mecanismo o papel exercido pelas interleucinas 12 e 18 no desencadear do processo. Essas citocinas são de fundamental importância na ativação dos linfócitos $T$ helper e, conseqüentemente, nas etapas sucessoras. (Mazzeo et al., 1998). 


\section{A imunologia e a endometriose}

Quando o tecido endometrial reflui pelas tubas e atinge a cavidade pélvica, ocorre uma resposta imune celular (Th1) e humoral (Th2). A resposta Th1 envolve os macrófagos peritoneais que fagocitam o tecido, neste caso representando o antígeno, processam-no no ambiente intracelular, exteriorizando fragmentos desse tecido através do complexo principal de histocompatibilidade classe 2 ativando os linfócitos T helper que , por sua vez, estimulam as células exterminadoras naturais ("natural killer") a destruírem o macrófago e, conseqüentemente, o antígeno nele contido. A resposta Th2 participa com a secreção de anticorpos específicos. Esse é o mecanismo de funcionamento normal do sistema imunológico que ocorre em mulheres hígidas, lembrando que o refluxo menstrual é um fenômeno universal (Berkkanoglu e Arici, 2003).

Desde a proposição inicial da teoria imunológica, no início da década de 1980, aceitou-se que, na mulher portadora de endometriose, o mecanismo fisiológico apresentava deficiências. Nessa ocasião, Weed e Arquembourg observaram que a freqüência de endometriose associada à infertilidade era muito elevada, principalmente relacionada à infertilidade secundária na qual cerca de 18 a $38 \%$ dos casos por eles estudados, mesmo quando não havia grandes distorções anatômicas, podiam ser atribuídos à doença em questão. Questionou-se, naquela ocasião, a razão pela qual a endometriose, mesmo em estádios iniciais, poderia determinar infertilidade e também como a infertilidade podia permanecer naquelas pacientes mesmo após a remoção dos focos da doença. Como resposta, postulou-se que, talvez, a endometriose causasse uma reação auto-imune com secreção de proteínas pelos focos ectópicos, que não conseguiriam ser removidas e, então, desencadeariam um sinal para que os mecanismos imunológicos de fagocitose e remoção de debris as depurassem como elementos antigênicos. A velocidade e capacidade de remoção de tais proteínas, características individuais de cada paciente, poderiam explicar como algumas delas conseguiam conceber, mesmo com endometriose 
avançada, e outras não o faziam, apesar de doença leve. Afirmou-se que, como a reação auto-imune podia ser revertida pela remoção cirúrgica dos endometriomas ou pela supressão prolongada da função ovariana, o sistema imune deveria estar envolvido na endometriose. Essa foi a primeira proposta da teoria imunológica na etiopatogenia da endometriose.

O fato de a endometriose promover ativação policlonal dos linfócitos $B$, o padrão familiar de ocorrência, o dano tecidual causado e o envolvimento de diversos órgãos, além do predomínio em mulheres e coexistência de outras doenças auto-imunes permitiram levantar a hipótese de a endometriose também poder ser considerada doença auto-imune (Nothnick, 2001).

Auto-anticorpos podem estar presentes e imunoglobulinas podem estar alteradas na endometriose, demonstrando o envolvimento da imunidade humoral na etiopatogenia do processo (Badawy et al., 1989). O anticorpo antinuclear, anticoagulante lúpico e anticorpo anti-lgG podem estar aumentados em pacientes com endometriose (Gleicher et al., 1987) e estudo mais recente, realizado em nosso meio por Pasoto et al. (2005), também mostrou aumento dos anticorpos antinucleares na endometriose, corroborando a hipótese de que o sistema imune apresente alguma falha em seus mecanismos reguladores nessas pacientes. Ainda em nosso meio, Podgaec (2006) estudou as respostas Th1 e Th2 em pacientes com endometriose e encontrou aumento das dosagens de interferon-gama, da interleucina-10 e alteração nas relações entre as citocinas do braço Th1 e Th2 apontando a ativação das duas vias na doença.

Além das alterações dos mecanismos imunológicos humorais, os mecanismos celulares também se modificam na endometriose. Dmowski et al., em 1981, apresentaram o primeiro trabalho afirmando que as mulheres com endometriose tinham imunidade celular deficiente. A partir de então, foram demonstradas diferenças nos números absoluto e relativo de linfócitos T auxiliar (Th) e T supressor na circulação periférica e no fluido peritoneal (Badawy et al., 1987), redução significativa na capacidade citotóxica das 
células natural-killer (Oosterlynck et al., 1991), aumento dos níveis das interleucinas 6 e 10 no fluido peritoneal (Punnonen et al, 1996), redução da função ativadora das células T auxiliares tipo 1 (Th1) do ambiente peritoneal, facilitando o implante e o crescimento do tecido endometrial ectópico (Wu e Ho, 2003), aumento do número e da concentração de macrófagos ativados no fluido peritoneal e também dos produtos destes macrófagos, como o fator de necrose tumoral alfa (TNF- $\alpha$ ), a interleucina 6 (IL-6), o fator de crescimento transformador beta 1 (TGF $\beta 1$ ) (D'Hooghe et al., 2001; Pizzo et al., 2002) e o fator de crescimento dos hepatócitos (Khan et al., 2006) . Observou-se que, na endometriose, os macrófagos infiltravam o tecido endometrial ectópico, desencadeando a resposta imunológica, que resultava num acúmulo de fluido peritoneal com níveis elevados de citocinas próinflamatórias do braço Th1 (resposta imune celular), como IL-6, IL-1 fração $\beta$ e TNF-a (Punnonen et al., 1996).

Os macrófagos peritoneais são ativados e estimulam linfócitos, culminando com a secreção de citocinas, que modulam o crescimento e o comportamento inflamatório dos implantes endometriais (Roitt et al., 2003). A secreção de proteínas mitogênicas pelas lesões endometrióticas contribui significativamente com os fenômenos de adesão, proliferação, neoangiogênese e quimioatração celular aos focos de endometriose recémimplantados (Lebovic et al, 2001). As células "natural killer" têm sua capacidade citotóxica reduzida, contribuindo para pior desempenho do sistema dependente das células para a defesa contra o implante endometrial ectópico (Berkkanoglu e Arici, 2003). 


\section{Papel das citocinas na etiopatogenia da endometriose}

Em 1997, Nisolle e Donnez propuseram que a endometriose ovariana, peritoneal e de septo retovaginal seriam doenças distintas, englobadas numa única entidade. Apesar dessa diferença, já aceita atualmente por parte dos estudiosos no assunto, também se postula que tais doenças se desenvolvem por existir alteração imunológica basal prévia na paciente, sendo que a função das citocinas tem papel de relevância no quadro em questão.

Para que um fragmento de tecido endometrial refluído pelas trompas consiga se implantar e desenvolver no sítio ectópico, uma sucessão de eventos se faz necessária. As etapas mais importantes são a adesão, implantação, angiogênese, progressão e infiltração. Em todos os processos anteriores, as citocinas estão envolvidas (Harada et al., 2001).

Em 1999, Koninckx et al. propuseram uma nova teoria etiopatogênica, por eles chamada teoria da doença endometriótica, que considera a endometriose uma doença semelhante a um tumor benigno. Seu embasamento, para tal, fundamentou-se nas evidências de que na endometriose havia redução da imunidade celular, redução da atividade das células "natural-killer", favorecimento hereditário à aquisição da doença e aspectos genéticos alterados. Destacou o envolvimento de algumas citocinas, comprovando o aumento das concentrações do fator transformador de crescimento beta (TGF-beta) e fator de crescimento endotelial vascular (VEGF) no fluido peritoneal, o que favoreceria a neovascularização necessária para o crescimento do foco endometriótico.

O fluido peritoneal é o principal fator de controle do microambiente peritoneal. Seu volume varia com a época do ciclo menstrual, atingindo um máximo no período ovulatório. Dentre seus componentes, encontram-se diversas células imunológicas, como macrófagos, células mesoteliais, linfócitos e eosinófilos (Harada et al., 2001). 
O possível processo inflamatório pélvico local que existe na endometriose determina alterações nas células contidas no líquido peritoneal, bem como em outros elementos, incluindo até o volume de líquido que, conforme demonstrado por Syrop e Halme, em 1987, é menor nas pacientes com endometriose quando comparadas às pacientes inférteis sem endometriose.

A resposta inflamatória associada à endometriose, o reparo tecidual e a neovascularização dependem dos macrófagos do fluido peritoneal e de seus produtos de secreção, particularmente das citocinas. Os macrófagos teciduais na endometriose estão mais ativados e, por isso, secretam maiores quantidades de citocinas (Halme et al., 1984). Diversos estudos propuseramse a analisar as diferentes citocinas conhecidas e seu comportamento na endometriose. Foi comprovada a maior secreção de IL-1, IL-6 , IL-8 , TNFalfa , TGF-beta e VEGF no fluido peritoneal de pacientes com endometriose ( Barcz et al., 2000; Iwabe, 2002; Khan et al., 2002; Wu e Ho, 2003). Em outros estudos, foram encontradas menores concentrações de outras citocinas, como o interferon-gama, sendo que as mesmas sofreram elevação quando as pacientes foram tratadas com análogos do GnRH (Ho et al., 1996). Há ainda pesquisadores que não encontraram diferenças significativas nas concentrações de determinadas citocinas no fluido peritoneal comparando mulheres hígidas e portadoras de endometriose, bem como entre pacientes com outras doenças pélvicas e pacientes com endometriose, como o estudo das concentrações de IL-6 nesses dois grupos, realizado por Buyalos et al. em 1992.

Uma visão mais geral do processo permite enquadrar a endometriose num processo inflamatório com fenômenos locais de reparação, envolvendo a ativação de polimorfonucleares e células mononucleares que, quando ativadas, secretam citocinas de uma maneira peculiar que permite a criação de um microambiente favorável à implantação das células endometriais refluídas ou metaplásicas (Pizzo et al., 2002). 
A necessidade da busca de métodos pouco ou minimamente invasivos para o diagnóstico da endometriose motiva estudiosos há anos. $O$ padrão-ouro atualmente aceito é a abordagem cirúrgica com obtenção de amostras para confirmação anatomopatológica (Giudice e Kao, 2004). Isso envolve custos pessoais e econômicos elevados, afastamento do trabalho e atividades cotidianas, além dos riscos decorrentes da internação hospitalar, anestesia e cirurgia.

\section{A interleucina 12}

A identificação e purificação da interleucina 12 (IL-12) foi feita por Kobayashi et al (1989), quando buscavam uma explicação para a proliferação de células natural-killer (NK).

Evidências prévias mostravam a necessidade de linfócitos $B$, células CD4 e altas concentrações de interleucina 2 para que se obtivesse a proliferação do clone NK. O mecanismo exato para que os eventos ocorressem era desconhecido, mas reconhecia-se um papel importante do interferon-gama no início do processo. Kobayashi et al. (1989) estimularam os clones de células B linfoblastoíticas infectadas com o vírus Epstein-Barr e então encontraram uma nova citocina por elas secretada, que era diretamente envolvida na produção de interferon-gama, na citotoxicidade das células NK e também aumentava a resposta das células $T$ a agentes específicos. Essa citocina foi chamada inicialmente de "Natural Killer Stimulatory Factor (NKSF)", devido às suas propriedades biológicas. Recentemente, passou a ser denominada interleucina 12.

Sua estrutura molecular é composta de um dímero glicoproteico de peso $70 \mathrm{KDa}$, dividida em duas cadeias, leve e pesada, com respectivamente 35 e $40 \mathrm{KDa}$ (Barcz et al., 2000). A expressão das duas cadeias é necessária para que a IL-12 seja funcionalmente ativa; a cadeia leve pode ser codificada pela maioria das células do organismo, mas a cadeia pesada só é produzida pelas células ligadas à função biológica desta 
citocina, principalmente as células mielomonocíticas representadas pelos macrófagos (Mazzeo et al., 1998). O conhecimento da necessidade da expressão das duas cadeias para a ação da IL-12 foi demonstrado no estudo de D'Andrea et al. em 1992. Esses autores verificaram que se células periféricas monocíticas eram estimuladas com cepas de Staphylococcus aureus Cowan I, cujo controle infeccioso dependia da resposta imune celular tipo Th1, havia grande liberação do complexo dimérico de $70 \mathrm{KDa}$; por outro lado, quando se administrava apenas uma das cadeias, leve (35KDa) ou pesada (40KDa), às células previamente infectadas, a resposta imune era extremamente deficitária permitindo o alastramento da infecção.

Além da informação da necessidade das duas cadeias para a função imune adequada, sabe-se que a cadeia pesada, isoladamente, atua como antagonista natural da própria IL-12, conforme demonstraram Somigliana et al., em 1999.

A IL-12 é considerada uma molécula-chave do sistema imune. Suas atividades primordiais exercem-se sobre as células T e NK(D'Andrea et al, 1992), a saber:

- indução da transcrição e secreção de outras citocinas, principalmente interferon-gama;

- aumento da citotoxicidade das células NK;

- indução da proliferação das células NK.

Essas ações têm início a partir do estímulo que ocorre quando a IL-12 induz a produção de interferon-gama sobre as células T e NK, controlando, portanto, a diferenciação das células $\mathrm{T}$ primordiais para o padrão Th1 (Somigliana et al., 1999).

A IL-12 é um elemento de grande importância no equilíbrio entre as respostas imunes Th1/Th2. O receptor para IL-12 é composto de duas cadeias, ditas beta-1 e beta-2, expressas conjuntamente apenas nas células do padrão Th1. As células do padrão Th2 podem expressar a cadeia beta-1, 
mas a cadeia beta-2 é induzida pelo interferon-gama e inibida pela IL-4 (Gazvani et al., 2001). A expressão do receptor incompleto torna-o nãofuncional.

Em 2004, Ledée-Bataille et al. estudaram o papel das interleucinas 12 e 18 em pacientes com falhas repetidas de implantação após fertilização assistida. Estudos anteriores mostravam que, em altas concentrações, tanto a IL-12 isolada quanto em sinergismo com IL-18 favoreciam abortamentos, mas em doses baixas ou fisiológicas eram necessárias nos estágios iniciais da implantação para a ocorrência da remodelação vascular e estabelecimento das relações materno-fetais iniciais (Yoshino et al, 2001; Chaouat et al, 2002). Confirmaram, nesse estudo, o envolvimento da IL-12 em altas concentrações nos abortamentos precoces e falhas repetidas de implantação, atribuindo esse fato à ativação das células NK e ao excesso de produção de interferon-gama.

Ainda em estudos relacionados à reprodução humana, outros pesquisadores investigaram o padrão de resposta imune predominante em abortamentos de repetição e a possibilidade de alguma ação atribuível às interleucinas. Wilson et al. (2004) estudaram 75 mulheres, sendo 25 nãogestantes sem antecedentes de abortamentos sucessivos e 50 com antecedentes de pelo menos 3 abortamentos prévios; encontraram níveis significativamente mais elevados de IL-12 e interferon-gama nas pacientes com abortamentos de repetição.

Visto já haver diversos trabalhos com IL-12 em vasta gama de doenças, grupos de pesquisadores aplicaram à endometriose raciocínios semelhantes, estudando o papel da citocina na mesma. Talvez a IL-12 pudesse ser um dos fatores responsáveis pela falha do controle das células NK no combate ao foco ectópico (Barcz et al., 2000).

Mazzeo et al, em 1998, realizaram um estudo com a dosagem da IL12 e da subunidade de $40 \mathrm{KDa}(\mathrm{p} 40)$ no fluido peritoneal de 33 pacientes com endometriose comprovada por videolaparoscopia e 40 pacientes sem endometriose e encontraram concentrações semelhantes da IL-12 total em 
ambos os grupos, porém concentrações mais elevadas da subunidade p40 no grupo com endometriose. A razão $\mathrm{IL}-12+\mathrm{p} 40 / \mathrm{IL}-12$ revelou-se diretamente proporcional à severidade da endometriose, mostrando haver um desequilíbrio nas portadoras da doença quanto à produção de IL-12, com aumento da proporção da cadeia pesada que compete em nível de receptor com a IL-12 clássica, inibindo suas funções.

Em 1999, Somigliana et al. propuseram o uso de modelos experimentais animais para o estudo da endometriose e citocinas. Inicialmente, estudaram ratos imunologicamente competentes, que foram submetidos à inoculação de implantes peritoneais de endometriose e sacrificados após 3 semanas da intervenção, quando os implantes eram analisados quanto à área e ao peso. Posteriormente, o mesmo modelo foi usado e nos animais previamente inoculados foi administrada IL-12; quando sacrificados no mesmo tempo para observação constatou-se que a adição de IL-12 foi capaz de prevenir os implantes e de reduzir o peso e a área dos tecidos em que conseguiram se implantar, corroborando a teoria de que a IL12 atuava como molécula fundamental no estímulo inicial da resposta imune celular contra o endométrio ectópico.

Em análise do fluido peritoneal de pacientes com e sem endometriose, Gazvani et al. (2001) estudaram as concentrações de IL-12 e encontraram distribuição similar nos dois grupos, sem diferenças nos diversos estádios da doença, nas fases do ciclo menstrual ou quanto às queixas de dismenorréia, infertilidade ou dor pélvica crônica.

Somigliana et al., também em 2001, estudaram em modelos animais os mecanismos imunológicos envolvidos na endometriose e a participação específica da IL-12. Inocularam tecido endometrial na cavidade peritoneal de ratos modificados geneticamente, divididos em dois grupos, sendo o primeiro deficiente em beta2-microglobulina (o que sabidamente os deixava com o número absoluto e relativo de linfócitos $\mathrm{T}$ reduzido) e o segundo deficiente na cadeia pesada da IL-12 (também comprometendo a resposta imune celular). Seus resultados não só apontaram que nos animais do grupo 
deficiente na cadeia p40 da IL-12 houve maior facilidade no crescimento e desenvolvimento dos implantes inoculados, mas também que em ambos os grupos a progressão da endometriose foi maior do que quando comparados a um terceiro grupo imunologicamente competente.

Em 2004, Gallinelli et al. estudaram o comportamento da IL-12 e IL-13 em 80 pacientes submetidas à videolaparoscopia por diferentes causas, como endometriose, dor pélvica, infertilidade, reanastomose ou laqueadura tubárea. A IL-13 é uma interleucina envolvida no estímulo da secreção de IL4 no fenótipo Th2. Os resultados mostraram aumento dos níveis de IL-12 no fluido peritoneal das pacientes com endometriose estádios III ou IV, quando comparadas às demais pacientes e, com relação à $\mathrm{IL}-13$, revelaram 0 contrário, sendo as dosagens peritoneais maiores nas portadoras de outras doenças quando comparadas às pacientes com endometriose, independentemente da severidade da mesma.

\section{$\underline{\text { A interleucina } 18}$}

A interleucina 18 (IL-18) foi inicialmente denominada Fator Indutor do Interferon Gama. Trata-se de uma glicoproteína membro da superfamília da interleucina 1, sendo secretada por diversos tipos celulares. No sangue periférico, é liberada como pró-IL-18, molécula com peso molecular de $24 \mathrm{KDa}$, e posteriormente passa por processo de clivagem extracelular pela enzima conversora da IL-1, transformando-se na IL-18 ativa, agora com peso de 18KDa (Arici et al., 2003). Em sua produção, estão envolvidos, principalmente, os macrófagos ativados.

A IL-18 tem participação nos dois braços da resposta imune (Th1 e Th2). Isoladamente, a IL-18 é uma citocina promotora da resposta Th2 com estímulo à produção de angiopoetina 2, aumentando os fatores vasculares locais, além de favorecer a liberação de IL-4, IL-5 , IL-10 e IL-13 (Zhang et al, 2004). Pode, também, comportar-se como uma citocina Th1, agindo sinergicamente com a IL-12, co-estimulando a produção de interferon-gama 
e, conseqüentemente, participando da ativação de células $\mathrm{T}$ e NK. Experimento realizado em 2001, por Esfandiari et al., mostrou que, em ratas com lúpus eritematoso sistêmico induzido, a adição de IL-12 associada a IL18 exacerbava o "rash" cutâneo em asa de borboleta, mas a adição isolada de IL-18 resultava na remissão do "rash" facial e aumentava os níveis de auto-anticorpos, mostrando a participação da IL-18 ora na resposta Th1, ora na Th2.

Conforme já mencionado anteriormente, a IL-18 é necessária em doses fisiológicas para o processo de implantação da gestação inicial, mas em doses elevadas tem participação nos abortamentos de repetição (Chaouat et al., 2002). A resposta básica Th1 é fundamental no processo inicial de implantação para haver estimulação e ativação das células NK uterinas, que, por sua vez, seriam essenciais no estabelecimento da angiogênese endometrial (Ledée-Bataille et al, 2005).

Assume-se, atualmente, que a IL-18 tem as seguintes funções biológicas ( Gracie et al., 2003):

- é o mais potente indutor da produção e secreção do interferon-gama;

- induz a produção de IL-12 e TNF-alfa;

- favorece a liberação de IL-4, IL-5, IL-10 e IL-13;

- $\quad$ participa dos dois braços de resposta imune Th1 e Th2.

Arici et al., em 2003, coletaram o fluido peritoneal de 74 pacientes durante a videolaparoscopia, sendo 50 portadoras de endometriose nãotratada, 8 com endometriose tratada com análogos do $\mathrm{GnRH}$ previamente e 18 sem endometriose, e nelas dosaram a concentração de IL-18 no fluido peritoneal. Seus resultados mostraram que a concentração de IL-18 no grupo das pacientes com endometriose era significativamente maior que naquelas sem a doença, salientando, ainda, que, na fase secretora, as concentrações eram sempre mais elevadas em todos os grupos. Houve ainda relação estatisticamente significativa quando a endometriose era 
peritoneal (maiores concentrações) e comparada à das pacientes com endometriomas ovarianos.

Em 2004, Oku et al. compararam as concentrações sérica e no fluido peritoneal de IL-18 de 39 pacientes com endometriose e 19 sem a doença. As concentrações no fluido peritoneal das portadoras de endometriose foram significativamente superiores às das pacientes sem a doença, mas em relação às concentrações séricas não se encontraram diferenças estatísticas nem quando se considerou o estadiamento segundo a Sociedade Americana de Medicina Reprodutiva. Em outro estudo, Zhang et al., em 2004, estudaram 44 pacientes submetidas à videolaparoscopia, sendo 22 delas com endometriose e 22 controles. Encontraram concentrações mais baixas da IL-18 no fluido peritoneal das portadoras de endometriose do que no grupo controle e também não observaram diferenças estatisticamente significativas nas concentrações séricas dos dois grupos estudados, mesmo considerando o estadiamento da doença ou as diferentes fases do ciclo. Interpretaram seus resultados defendendo a hipótese de que a redução da concentração da IL-18 determinaria prejuízo global nas funções imunológicas celulares, favorecendo o implante e o crescimento dos focos endometriais ectópicos.

Em nosso meio, Glitz (2006) não encontrou diferenças nas dosagens sérica e peritoneal de IL-18 entre um grupo de mulheres férteis sem endometriose comparado a outro grupo de pacientes com infertilidade e endometriose mínima ou leve, sugerindo que não seria a alteração da IL-18 a possível causa da associação de infertilidade e endometriose inicial.

Luo et al. (2006) estudaram a expressão do RNA mensageiro da IL18 no endométrio tópico e em focos de endometriose de um grupo de mulheres hígidas, comparando-as com pacientes com endometriose. Observaram que nas pacientes com a doença a expressão do RNA mensageiro da IL-18 estava significativamente diminuída tanto no endométrio tópico quanto ectópico, o que fortaleceria a hipótese da participação da IL-18 na etiopatogenia do processo. 
Conforme salientado, há incertezas sobre a etiopatogenia da endometriose, principalmente no âmbito da imunidade. Nesse quesito, as interleucinas 12 e 18 têm papel importante por atuarem como desencadeadoras das respostas imunes Th1 e Th2 a partir de estímulos sobre os linfócitos T primordiais (D’Andrea et al., 1992; Gazvani et al., 2002). Adicionalmente, são conflitantes os dados sobre a participação dessas interleucinas na endometriose pélvica. Esse estudo foi realizado visando a aprofundar os conhecimentos de modo a dirimir algumas dúvidas acerca da participação das interleucinas 12 e 18 em pacientes nesta doença, ressaltando a inexistência de outros estudos em que tenha sido feita a correlação das referidas citocinas com a fase do ciclo menstrual de coleta das amostras, o estadiamento, o local e a classificação histológica da doença. 
PROPOSICÃ̃O 


\section{Proposição}

Propusemo-nos neste estudo a:

1. avaliar o comportamento das interleucinas 12 e 18 em pacientes com endometriose pélvica através de suas dosagens no sangue e no fluido peritoneal;

2. relacionar em pacientes com endometriose, as dosagens séricas e no fluido peritoneal das interleucinas 12 e 18 com:

- a fase do ciclo menstrual;

- o quadro clínico;

- os locais de acometimento: peritônio, ovário e doença profunda;

- o estadiamento da endometriose

- a classificação histológica da endometriose. 
PACIENTES E MÉTODOS 


\section{Pacientes e Métodos}

Avaliamos 105 pacientes do sexo feminino que foram submetidas à videolaparoscopia no Setor de Endometriose do Hospital das Clínicas da Faculdade de Medicina da Universidade de São Paulo durante o período de abril de 2004 a dezembro de 2005. Foram subdivididas em dois grupos, casos e controles, após a realização do procedimento cirúrgico, de acordo com a presença ou ausência da endometriose. No grupo dos casos com endometriose foram incluídas 72 pacientes e no grupo controle 33.

O estudo foi aprovado pelo Comitê de Ética e Pesquisa do Hospital das Clínicas da Faculdade de Medicina da Universidade de São Paulo (anexo A).

Todas as pacientes leram e assinaram o termo de consentimento pósinformação (anexo B).

A Fundação de Amparo à Pesquisa do Estado de São Paulo (FAPESP) auxiliou a realização deste estudo com a aprovação de verba no processo 05/01218-3

\section{Critérios de inclusão}

Os critérios de inclusão para o grupo de pacientes com endometriose (anexos C, D e E) foram:

- $\quad$ idade entre 18 e 40 anos;

- $\quad$ endometriose confirmada histologicamente;

- ausência de doenças auto-imunes, confirmada através de anamnese e exames laboratoriais quando necessário;

- $\quad$ ciclos menstruais regulares; 
- não utilização de terapêutica hormonal nos 3 meses antecedentes ao procedimento cirúrgico, incluindo análogos do $\mathrm{GnRH}$, derivados progestogênicos e contraceptivos hormonais;

- $\quad$ ausência de contaminação hemática no fluido peritoneal.

Para o grupo controle (anexos C, D e E), foram selecionadas pacientes com quadro clínico sugestivo de endometriose, com indicação de videolaparoscopia, com os mesmos critérios de inclusão citados para o grupo dos casos, exceto pela confirmação da ausência de endometriose durante a cirurgia.

\section{Dinâmica do estudo}

As pacientes encaminhadas ao Setor de Endometriose do Hospital das Clínicas da Faculdade de Medicina da Universidade de São Paulo eram inicialmente submetidas à consulta ginecológica com avaliação das queixas clínicas, exame físico e exames subsidiários pertinentes, como a dosagem sérica do marcador tumoral CA-125 nos três primeiros dias do ciclo menstrual, ultra-sonografia pélvica e/ou transvaginal e, quando havia necessidade, ressonância nuclear magnética da pelve.

Nos casos em que a suspeita clínica, laboratorial (CA-125 maior ou igual a $100 \mu \mathrm{g} / \mathrm{mL}$ ) e/ou por imagem (cistos anexiais ou sinais de doença profunda) sugeriram endometriose, ou se houvesse normalidade nos exames, mas ausência de melhora com tratamento clínico com analgésicos e/ou anti-inflamatórios por 6 meses a 1 ano, a paciente era submetida à videolaparoscopia. Durante o procedimento, na dependência de terem sido observadas lesões compatíveis com endometriose, eram realizadas biópsias com posterior confirmação anatomopatológica. Quando confirmada a endometriose, a paciente era incluída no grupo de casos. Na ausência de lesões visíveis no intraoperatório, ela era incluída no grupo controle. 
Anotamos o dia do ciclo menstrual em que a paciente se encontrava no momento do procedimento cirúrgico. Dessa forma, subdividimos as pacientes em fase folicular e fase lútea e nelas avaliamos o comportamento das interleucinas 12 e 18.

Antes da anestesia geral para a videolaparoscopia, colheram-se $5 \mathrm{~mL}$ de sangue periférico em tubo seco. A paciente foi submetida à laparoscopia, seguindo a rotina habitual do serviço. Pela punção secundária, realizou-se a coleta de líquido peritoneal depositado em fundo de saco anterior e/ou posterior, variando de volume entre 2 e $10 \mathrm{~mL}$, e armazenado em tubo seco. O material foi encaminhado ao laboratório para ser centrifugado, aliquotado e congelado em freezer a $-20^{\circ} \mathrm{C}$. Depois de estocado, o mesmo somente foi descongelado com a coleta completa de todos os dados, para realização das dosagens das interleucinas 12 e 18.

Ainda durante o ato cirúrgico, foi observado o local dos implantes da endometriose. Foram consideradas três localizações para a classificação: doença peritoneal, ovariana e doença profunda (regiões retro-cervical, paracervical, septo reto-vaginal, reto-sigmóide, ureteres e bexiga). Para a análise estatística foi considerado como critério de gravidade a ordem crescente: doença peritoneal, doença ovariana e doença profunda infiltrativa, conforme postulado por Nisolle e Donnez (1997).

Em relação à avaliação das dosagens das interleucinas segundo a classificação histológica, agrupamos as pacientes em duas categorias histológicas (sem indiferenciação e com indiferenciação). O critério para tal divisão baseou-se na classificação histológica proposta por Abrão et al. (2003), com quatro tipos histológicos de apresentação da doença (estromal, bem-diferenciada, padrão misto de diferenciação e indiferenciada). As pacientes do grupo com endometriose foram subdivididas em dois subgrupos (sem indiferenciação e com indiferenciação). As classes histológicas estromal e bem-diferenciada foram categorizadas como "sem indiferenciação" ( $n=28$ ), enquanto as formas mista e indiferenciadas foram categorizadas como "com indiferenciação" ( $n=44)$, considerando o 
comportamento da doença estromal e bem-diferenciada menos agressivo e o comportamento da doença com padrões misto de diferenciação e indiferenciada mais agressivo.

\section{Estadiamento da Endometriose}

As pacientes com endometriose tiveram sua doença classificada durante o procedimento cirúrgico pelo critério da American Society for Reproductive Medicine (1996) em estádios de I a IV (Figura 1). Para melhor análise estatística, os estádios I e II foram agrupados como estádio inicial e os estádios III e IV foram agrupados como estádio avançado. 
FIGURA 1 - Classificação da endometriose proposta pela American Society for Reproductive Medicine (revisada em 1996).

$\begin{array}{llll}\text { Estádio I (mínima): } & 1-5 & \text { Estádio II (leve): } & 6-15 \\ \text { Estádio III (moderada): } 16-40 & \text { Estádio IV (severa): } & >40\end{array}$

\begin{tabular}{|c|c|c|c|c|}
\hline \multirow{3}{*}{ PERITÔNIO } & ENDOMETRIOSE & $<1 \mathrm{~cm}$ & $1-3 \mathrm{~cm}$ & $>3 \mathrm{~cm}$ \\
\hline & Superficial & 1 & 2 & 4 \\
\hline & Profunda & 2 & 4 & 6 \\
\hline \multirow{4}{*}{ OVÁRIO } & D superficial & 1 & 2 & 4 \\
\hline & Profunda & 4 & 16 & 20 \\
\hline & E superficial & 1 & 2 & 4 \\
\hline & Profunda & 4 & 16 & 20 \\
\hline \multirow{2}{*}{\multicolumn{2}{|c|}{$\begin{array}{l}\text { OBLITERAÇÃO DO FUNDO } \\
\text { DE SACO POSTERIOR }\end{array}$}} & \multicolumn{2}{|l|}{ Parcial } & Completa \\
\hline & & \multicolumn{2}{|l|}{4} & 40 \\
\hline \multirow{5}{*}{ OVÁRIO } & ADERÊNCIAS & $<$ 1/3 Envolvido & 1/3 - 2/3 Envolvidos & $>$ 2/3 Envolvidos \\
\hline & D Velamentosa & 1 & 2 & 4 \\
\hline & Densa & 4 & 8 & 16 \\
\hline & E Velamentosa & 1 & 2 & 4 \\
\hline & Densa & 4 & 8 & 16 \\
\hline \multirow{4}{*}{ ГROMPA } & D Velamentosa & 1 & 2 & 4 \\
\hline & Densa & $4 *$ & $8^{*}$ & 16 \\
\hline & E Velamentosa & 1 & 2 & 4 \\
\hline & Densa & $4 *$ & $8^{*}$ & 16 \\
\hline
\end{tabular}

* Se as fímbrias tubáreas estiverem totalmente envolvidas por aderências, mude o escore para 16.
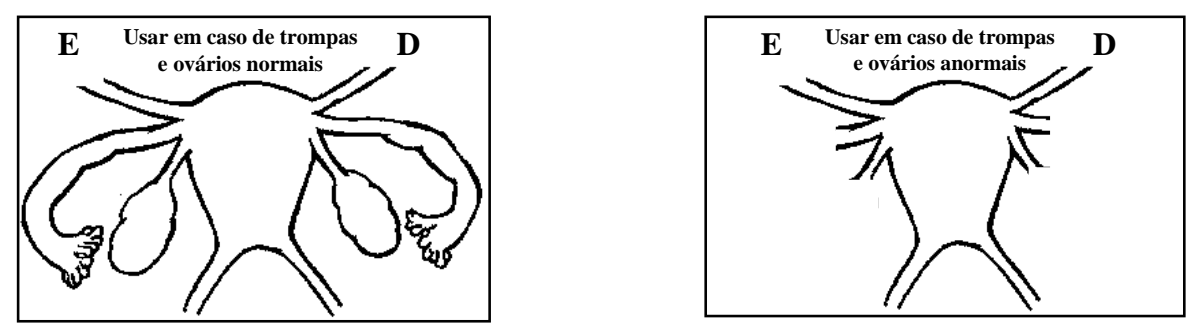


\section{Método laboratorial}

O método laboratorial utilizado para as dosagens das interleucinas 12 e 18 foi o ELISA, ténica de ensaio imunoenzimático quantitativo tipo sanduíche: anticorpos monoclonais específicos para as referidas interleucinas são pré-fixados em uma placa de ELISA. Padrões, amostras e os conjugados (anticorpos policlonais contra IL-12 e contra IL-18 ligados à enzima peroxidase) foram pipetados. Quaisquer IL-12 ou IL-18 presentes nas amostras ligaram-se aos anticorpos imobilizados e aos conjugados, formando um complexo anticorpo-antígeno-anticorpo conjugado. Após uma etapa de lavagem, para remover quaisquer substâncias não ligadas, uma solução contendo o substrato (tetrametilbenzidina + peróxido de hidrogênio) foi adicionada, observando-se o desenvolvimento de cor proporcionalmente à quantidade das interleucinas ligadas. A reação foi então estabilizada por meio da adição de uma solução de ácido sulfúrico $2 \mathrm{~N}$ e a intensidade da cor foi medida por um leitor de ELISA. Como padrões, foram usadas 6 soluções de concentrações diferentes e conhecidas de IL-12 e IL-18 recombinantes. Utilizamos os kits IL-12 (p70) Humana (Human IL-12 p70 Kit, BD Biosciences, San Diego, USA) para a IL-12 e IL-18 ELISA (IL-18 ELISA, IBL, Hamburg, Alemanha). O limite de detecção do kit de IL-12 preconizado pelo laboratório foi de $4 \mathrm{pg} / \mathrm{mL}$ e o do kit de IL-18 foi de 9,2 pg/mL.

Para o cálculo dos resultados, foram criadas curvas-padrão com base nos resultados dos padrões (média dos conjuntos de padrões ensaiados em duplicata), utilizando-se um programa de computador específico (SPSS versão 10.0). 


\section{Análise Estatística}

Para cada interleucina, foram comparadas as concentrações verificadas no sangue e no líquido peritoneal nos casos e nos controles. Foram avaliadas as médias (teste t de Student) e as proporções por faixa de dispersão (testes chi-quadrado e Fisher).

As variáveis quantitativas foram apresentadas descritivamente em gráficos. Os grupos foram comparados com o teste não paramétrico de Kruskal-Wallis; quando significante, complementou-se com o teste de Dunn para discriminar a(s) diferença(s).

Os valores de $\mathrm{p}<0,05$ foram considerados estatisticamente significantes.

Os casos foram categorizados para avaliação estatística segundo a fase do ciclo, sintomas, local da doença, estadiamento e classificação histológica . 
RESULTADOS 


\section{$\underline{\text { Resultados }}$}

Os dados do estudo foram obtidos através de comparações entre os resultados do grupo de pacientes com endometriose e do grupo controle em relação a diversos parâmetros.

Na tabela 1 está a distribuição das pacientes conforme sintomas, localização da doença, estadiamento e classificação histológica da endometriose .

Tabela 1 - Comparação entre os grupos controle e com endometriose em relação aos sintomas, locais de doença, estadiamento e classificação histológica

\begin{tabular}{|c|c|c|c|c|c|}
\hline \multirow[t]{2}{*}{ CARACTERÍSTICA } & \multicolumn{2}{|c|}{ GRUPO COM ENDOMETRIOSE } & \multicolumn{2}{|c|}{ GRUPO CONTROLE } & \multirow[t]{2}{*}{$\mathrm{p}$} \\
\hline & N & $\%$ & $\mathrm{~N}$ & $\%$ & \\
\hline DISMENORRÉIA SEVERA OU INCAPACITANTE & 47 & $83,9 \%$ & 9 & $16,0 \%$ & $0,001^{*}$ \\
\hline DISPAREUNIA DE PROFUNDIDADE & 36 & $51,4 \%$ & 12 & $36,3 \%$ & 0,153 \\
\hline ALGIA PÉLVICA ACÍCLICA & 44 & $62,8 \%$ & 13 & $39,3 \%$ & $0,025^{*}$ \\
\hline INFERTILIDADE & 26 & $37,1 \%$ & 8 & $25,0 \%$ & 0,227 \\
\hline ALTERAÇÃO INTESTINAL CÍCLICA & 37 & $52,8 \%$ & 2 & $6,0 \%$ & $0,001^{*}$ \\
\hline ALTERAÇÃO URINÁRIA CÍCLICA & 2 & $2,8 \%$ & 0 & $0 \%$ & 1 \\
\hline DOENÇA PERITONEAL & 33 & $47,1 \%$ & & & \\
\hline DOENÇA OVARIANA & 41 & $58,5 \%$ & & & \\
\hline DOENÇA PROFUNDA & 36 & $51,4 \%$ & & & \\
\hline ENDOMETRIOSE INICIAL (ESTÁDIOS I E II) & 28 & $38,9 \%$ & & & \\
\hline ENDOMETRIOSE AVANÇADA (ESTÁDIOS III E IV) & 44 & $61,1 \%$ & & & \\
\hline ENDOMETRIOSE MISTA E/OU INDIFERENCIADA & 44 & $61,1 \%$ & & & \\
\hline ENDOMETRIOSE ESTROMAL E/OU BEM DIFERENCIADA & 28 & $38,9 \%$ & & & \\
\hline
\end{tabular}

* $: p<0,05$

A avaliação das dosagens das interleucinas 12 e 18, comparando o grupo com endometriose em geral $(n=72)$ em relação ao grupo controle foi analisada, e os resultados estão apresentados na tabela 2. 
Tabela 2 - Comparação das dosagens das interleucinas 12 e 18 entre o grupo controle e o grupo de pacientes com endometriose (pg/mL)

\begin{tabular}{|c|c|c|c|c|}
\hline & IL 12 & & IL18 & \\
\hline & sangue & Fluido peritoneal & sangue & Fluido peritoneal \\
\hline Controle & $97,13+/-19,02$ & $29,20+/-10,21$ & $62,07+/-8,08$ & $112,51+/-29,24$ \\
\hline EDT & $152,14+/-22,59$ & $82,37+/-16,61$ & $70,52+/-0,00$ & $142,54+/-23,39$ \\
\hline $\mathrm{p}$ & 0,16 & $<0,001^{*}$ & 0,39 & 0,22 \\
\hline
\end{tabular}

Também procedemos à análise das dosagens das interleucinas $12 \mathrm{e}$ 18 em relação à fase do ciclo menstrual em que as pacientes foram submetidas ao procedimento videolaparoscópico. Os resultados estão apresentados na tabela 3 .

Tabela 3 - Comparação das dosagens das interleucinas 12 e 18 no sangue e no fluido peritoneal entre o grupo controle e pacientes com endometriose em relação à fase do ciclo menstrual (média +l- erro padrão em pg/mL)

\begin{tabular}{lccccc}
\hline & Controle & & \multicolumn{3}{c}{ ENDOMETRIOSE } \\
\hline & sangue & Fluido peritoneal & sangue & Fluido peritoneal \\
\cline { 6 - 7 } & & & & & \\
IL12 Fase folicular & $101.98+24.21$ & $36.04+13.2$ & & $125.25+19.46$ & $82.54+16.58$ \\
IL12 Fase lútea & $81.98+22.32$ & $7.83+3.83$ & $152.69+45.98$ & $40.56+14.2$ \\
& $p$ & 0,753 & 0,176 & 0,644 & 0,231 \\
& & & & \\
IL18 Fase folicular & $56.29+7.67$ & $126.62+37.05$ & $57.57+10.17$ & $159.98+29.94$ \\
IL18 Fase lútea & $80.12+23.25$ & $68.38+32.34$ & $56.49+26.09$ & $91.2+33.28$ \\
& $p$ & 0,542 & 0,444 & 0,542 & 0,479 \\
\hline
\end{tabular}

Comparamos as dosagens das interleucinas 12 e 18 entre o grupo controle e as pacientes com endometriose segundo os sintomas apresentados, conforme demonstrado na tabela 4 . 
Tabela 4 - Comparação das dosagens das interleucinas 12 e 18 no sangue e no fluido peritoneal entre o grupo controle e o grupo com endometriose, segundo os sintomas apresentados.

\begin{tabular}{|c|c|c|c|c|c|c|c|c|c|}
\hline \multirow{2}{*}{ Variável } & \multirow{2}{*}{ IL } & \multicolumn{3}{|c|}{ Controle } & \multicolumn{3}{|c|}{ Endometriose } & \multicolumn{2}{|c|}{$\mathbf{p}$} \\
\hline & & $\mathbf{n}$ & sangue & FP & $\mathbf{n}$ & sangue & FP & sangue & FP \\
\hline \multicolumn{10}{|c|}{ Dismenorréia severa } \\
\hline & 12 & 9 & $86.92+23.68$ & $35.94+23.17$ & 47 & $151.87+27.54$ & $82.21+20.54$ & 0,77 & $0,02^{*}$ \\
\hline & 18 & 9 & $97.16+13.19$ & $199.79+86.79$ & 47 & $77.59+16.5$ & $158.68+30.03$ & $0,01^{*}$ & 0,86 \\
\hline \multicolumn{10}{|c|}{ Dispareunia de profundidade } \\
\hline & 12 & 12 & $158.81+41.77$ & $44.83+23.39$ & 38 & $132.27+30.59$ & $101.62+29.25$ & 0,26 & $0,02^{*}$ \\
\hline & 18 & 12 & $82.45+13.81$ & $161.81+69.81$ & 38 & $61.34+14.05$ & $162.19+38.09$ & $0,03^{*}$ & 0,36 \\
\hline \multicolumn{10}{|c|}{ Dor acíclica } \\
\hline & 12 & 13 & $126.64+31.82$ & $40.08+19.91$ & 44 & $165.67+29.2$ & $101.93+26.14$ & 0,89 & $0,02^{*}$ \\
\hline & 18 & 13 & $49.86+11.05$ & $146+65.34$ & 46 & $86.45+17.32$ & $147.85+32.07$ & 0,46 & 0,47 \\
\hline \multicolumn{10}{|c|}{ Infertilidade } \\
\hline & 12 & 8 & $97.03+22.53$ & $44.53+25.55$ & 28 & $167.63+40.4$ & $122.76+41.61$ & 0,70 & 0,27 \\
\hline & 18 & 8 & $84.45+22.16$ & $173.65+90.26$ & 28 & $50.3+7.37$ & $103.22+25.09$ & 0,30 & 0,42 \\
\hline \multicolumn{10}{|c|}{ Alterações intestinais cíclicas } \\
\hline & 12 & 2 & $75.27+12.17$ & $11.28+7.28$ & 39 & $162.18+31.34$ & $105.59+29.56$ & 1,00 & 0,11 \\
\hline & 18 & 2 & $26.3+15.07$ & $59.99+20.98$ & 39 & $63.16+13.14$ & $161.87+30.5$ & 0,36 & 0,73 \\
\hline \multicolumn{10}{|c|}{ Alterações urinárias cíclicas } \\
\hline & 12 & 0 & & & 2 & $134.92+56.03$ & $380.86+300.85$ & & \\
\hline & 18 & 0 & & & 2 & $32.24+10.75$ & $210.65+77.38$ & & \\
\hline
\end{tabular}

*: $p<0,05$

Realizamos a avaliação das dosagens das interleucinas 12 e 18 entre o grupo de pacientes com endometriose segundo o local da doença e os resultados estão representados na tabela 5 .

Tabela 5 - Comparação entre as dosagens das interleucinas 12 e 18 no sangue e no fluido peritoneal em relação à localização da doença, segundo critério de gravidade $(\mathrm{pg} / \mathrm{mL})$.

\begin{tabular}{|c|c|c|c|c|c|c|c|c|}
\hline \multirow{2}{*}{\multicolumn{2}{|c|}{ Variável }} & \multicolumn{2}{|c|}{ Ovário (n=21) } & \multicolumn{2}{|c|}{ Peritônio (n=15) } & \multicolumn{2}{|c|}{ Profunda $(n=36)$} & \multirow[b]{2}{*}{ p } \\
\hline & & Média & $\begin{array}{c}\text { Erro } \\
\text { padrão }\end{array}$ & Média & $\begin{array}{l}\text { Erro } \\
\text { padrão }\end{array}$ & Média & $\begin{array}{c}\text { Erro } \\
\text { padrão }\end{array}$ & \\
\hline \multirow[t]{2}{*}{ IL - 12} & $\mathrm{sg}$ & 146,43 & 43,86 & 96,86 & 28,00 & 178,50 & 35,24 & 0,31 \\
\hline & $\mathrm{FP}$ & 53,02 & 15,20 & 71,59 & 19,32 & 103,98 & 30,83 & 0,62 \\
\hline \multirow[t]{2}{*}{ IL - 18} & $\mathrm{sg}$ & 68,91 & 17,32 & 103,56 & 38,08 & 57,70 & 13,43 & 0,42 \\
\hline & $\mathrm{FP}$ & 142,26 & 56,52 & 109,89 & 37,86 & 156,30 & 29,95 & 0,31 \\
\hline
\end{tabular}


De acordo com o estadiamento proposto pela Sociedade Americana de Medicina Reprodutiva dividimos as pacientes do grupo com endometriose. Realizamos a comparação das dosagens das interleucinas 12 e 18 entre o grupo controle e o grupo com endometriose que também foi subdividido segundo o estadiamento. Os resultados estão apresentados nas tabelas 6 e 7.

Tabela 6 - Comparação das dosagens da interleucina 12 no sangue e no fluido peritoneal entre o grupo controle e pacientes com endometriose subdivididas segundo o estadiamento (ASRM, 1996; média +l- erro padrão em pg/mL)

\begin{tabular}{lcccc}
\hline$\underline{\text { IL-12 }}$ & \multicolumn{2}{c}{ estádios I/II $(\mathbf{n}=\mathbf{2 8})$} & \multicolumn{2}{c}{ estádios $I I I / I V(\mathbf{n}=44)$} \\
\hline & sangue & FP & sangue & FP \\
média & 82,04 & 62,54 & 196,74 & 94,98 \\
erro padrão & 16,63 & 14,13 & 33,91 & 25,61 \\
p-value & $0,007^{*}$ & 0,71 & & \\
\hline
\end{tabular}

$*: p<0,05$

Tabela 7 - Comparação das dosagens da interleucina 18 no sangue e no fluido peritoneal entre o grupo controle e pacientes com endometriose subdivididas segundo o estadiamento (ASRM, 1996; média +l- erro padrão em $\mathrm{pg} / \mathrm{mL}$ )

\begin{tabular}{lcccc}
\hline$\underline{\text { IL-18 }}$ & \multicolumn{2}{c}{ estádios I/II(n=28) } & \multicolumn{2}{c}{ estádios III/IV(n=44) } \\
\hline & sangue & FP & sangue & FP \\
média & 51,28 & 97,21 & 82,77 & 171,38 \\
erro padrão & 10,56 & 27,21 & 17,49 & 33,65 \\
p-value & 0,63 & 0,05 & & \\
\hline
\end{tabular}


De acordo com a classificação histológica da endometriose realizamos a comparação das dosagens de IL-12 e IL-18 no sangue e no fluido peritoneal. Verificamos que não houve diferença estatisticamente significante entre as categorias histológicas e as dosagens das referidas interleucinas, mas houve uma tendência ao aumento da IL-12 sérica em pacientes com formas mais indiferenciadas da endometriose. Os resultados estão demonstrados nas tabelas 8 e 9.

Tabela 8 - Comparação das dosagens da interleucina 12 no sangue e no fluido peritoneal no grupo de pacientes com endometriose, de acordo com a categoria histológica .

\begin{tabular}{cccccccc}
\hline & & \multicolumn{2}{l}{ IL12 Fluido peritoneal } & & \multicolumn{2}{l}{ L12 Sérica } & \\
\cline { 6 - 7 } Categoria Histológica & $n$ & média & $\begin{array}{c}\text { erro } \\
\text { padrão }\end{array}$ & $n$ & média & $\begin{array}{c}\text { erro } \\
\text { padrão }\end{array}$ \\
\hline Sem indiferenciação & 28 & 63,21 & 13,77 & 28 & 104,04 & 21,01 \\
Com indiferenciação & 44 & 94,56 & 25,70 & 44 & 182,74 & 33,86 \\
p & & 0,9120 & & & 0,1149 & \\
\hline
\end{tabular}

Tabela 9 - Comparação das dosagens da interleucina 18 no sangue e no fluido peritoneal no grupo de pacientes com endometriose, de acordo com a categoria histológica.

\begin{tabular}{|c|c|c|c|c|c|c|}
\hline \multirow[b]{2}{*}{ Categoria Histológica } & \multicolumn{3}{|c|}{ IL18 Fluido peritoneal } & \multicolumn{3}{|c|}{ IL18 Sérica } \\
\hline & $\mathrm{n}$ & média & $\begin{array}{c}\text { erro } \\
\text { padrão }\end{array}$ & $\mathrm{n}$ & média & $\begin{array}{c}\text { erro } \\
\text { padrão }\end{array}$ \\
\hline Sem indiferenciação & 28 & 123,39 & 29,30 & 28 & 80,17 & 22,89 \\
\hline Com indiferenciação & 44 & 154,72 & 33,55 & 44 & 64,39 & 12,16 \\
\hline $\mathrm{p}$ & & 0,8524 & & & 0,7859 & \\
\hline
\end{tabular}


DISCUSSÃO 


\section{Discussão}

Nosso trabalho avaliou o comportamento das interleucinas 12 e 18 no sangue e no fluido peritoneal em um grupo controle composto por 33 pacientes com quadro clínico sugestivo e ausência comprovada de endometriose e em 72 pacientes com endometriose com diferentes características. Até o presente momento inexiste na literatura trabalho semelhante que correlacione essas duas citocinas com a fase do ciclo menstrual, sintomas, estadiamento, local e classificação histológica da doença, o que apresenta um panorama global dos diversos aspectos da endometriose, todos envolvidos no entendimento completo da mesma. $O$ estudo desses parâmetros correlacionados às dosagens das referidas interleucinas poderia representar uma nova proposta no entendimento mais claro da fisiopatologia da endometriose.

Sabidamente, a IL-12 e a IL-18 participam ativamente da base imunológica, fundamentalmente da reposta Th1 (Gazvani et al., 2001; Gracie et al., 2003). Reconhecemos ser esse um dos principais mecanismos responsáveis pelo desenvolvimento da doença, daí a importância do conhecimento mais profundo acerca do comportamento de cada elemento dele constituinte nos eventos relacionados ao processo etiopatogênico (Podgaec et al., 2007).

Quando o tecido endometrial refluído pelas tubas uterinas atinge a cavidade pélvica, inicia-se uma resposta imune. Os macrófagos peritoneais são as primeiras células recrutadas, reconhecem o tecido endometrial como antigênico e fagocitam-no para processá-lo no ambiente intracelular. Partículas do tecido fagocitado são expostas na superfície dos macrófagos e reconhecidas por linfócitos Th primordial. Nesse momento, com a participação das interleucinas 12 e 18, há a transformação desses linfócitos Th primordial em Th1, determinando a via de resposta imune celular. 
A IL-12 atua nesse processo aumentando a citotoxicidade das células NK e estimulando a secreção de outras citocinas, principalmente 0 interferon-gama. A IL-18 igualmente atua de modo significativo, induzindo a produção e secreção do interferon-gama, além de estimular a própria produção da IL-12, do TNF-alfa e de citocinas do braço Th2. Portanto, sob estímulo das interleucinas 12 e 18 sintetizadas por células NK e macrófagos, os linfócitos Th primordial diferenciam-se em Th1 (Podgaec \& Abrão, 2005).

Assumindo-se que a ocorrência da resposta imune Th1 seja de fundamental importância para o controle do ambiente peritoneal com limpeza das células refluídas, inferimos que o mecanismo fisiológico anteriormente descrito apresente alterações na endometriose, propiciando o implante e crescimento dos focos ectópicos. Hsu et al. (1997) creditaram ao desequilíbrio entre as respostas Th1 e Th2, pendendo para a resposta Th2, a explicação para as alterações imunológicas encontradas em mulheres com endometriose. A importância de tal desequilíbrio já havia sido demonstrada em outros processos fisiológicos, como nas falhas de implantação e abortamentos de repetição (Chaouat et al., 2002; Lédée-Bataille et al., 2004). Podgaec (2006) encontrou aumento das citocinas Th2 nas pacientes com endometriose.

Apesar do melhor conhecimento dos mecanismos envolvidos na etiopatogenia da endometriose diversos aspectos ainda permanecem obscuros, sendo vasto o campo de pesquisa nesta área. Trabalhos recentes em imunologia têm trazido esclarecimentos da base fisiopatológica do processo explicando-nos os passos fundamentais que culminam na permissão para o implante, crescimento e desenvolvimento do tecido endometrial em sítio extra-uterino. Além disso, as terapias atualmente disponíveis para o tratamento da doença baseiam-se na citorredução e citossupressão das células ectópicas, logo, quando suspensas, não conseguem impedir a recidiva ou o avanço da mesma (Lebovic et al., 2001). Por outro lado as terapias mais eficazes existentes em nossos dias apóiamse na interrupção com bloqueio do fluxo menstrual (Petta et al.,2005, de Sa Rosa e Silva et al., 2006; Hansen e Eyster, 2006); salientando que muitas 
das pacientes têm desejo reprodutivo, essas técnicas tornam-se dificultosas à obtenção da gestação. O entendimento mais profundo dos mecanismos fisiopatológicos envolvidos na gênese da endometriose poderia permitir o desenvolvimento de terapias mais adequadas ao combate das causas fundamentais do processo com ações mais duradouras e efetivas.

A fase do ciclo menstrual pode ser entendida como relevante para 0 entendimento do comportamento das interleucinas na endometriose. Sabendo que o estímulo à resposta ocorre durante a fase menstrual, que é justamente quando acontece a chegada do tecido endometrial à cavidade pélvica, poderíamos inferir que as dosagens das interleucinas relacionadas a essa resposta deveriam ser mais elevadas nessa época. Esse, no entanto, não foi o resultado observado por Gazvani et al. (2001) que não encontraram diferenças nas dosagens de IL-12 nas fases folicular e lútea. Arici et. al (2003) encontraram elevação das dosagens peritoneais de IL-18 na fase lútea em comparação com a fase folicular. Luo et al. (2006) também avaliaram as diferentes fases do ciclo em relação à secreção de IL-18 e verificaram que, em mulheres hígidas, a secreção dessa citocina estava bastante elevada na fase secretória quando comparada à fase folicular, entretanto tal diferença não era observada entre as pacientes com endometriose. Podgaec et al. (2007), estudando outra citocinas envolvidas nas respostas Th1 e Th2 em pacientes com endometriose, encontrou aumento das dosagens de IL-10 na fase folicular em mulheres com a doença quando comparadas a um grupo controle sem a doença. Nossos resultados em relação à fase do ciclo não mostraram diferenças nas dosagens sérica ou no fluido peritoneal das interleucinas 12 e 18.

Estudamos os dois grupos (casos e controles) em relação aos sintomas apresentados. Ressaltamos que nosso grupo controle era composto por mulheres com quadro clínico sugestivo de endometriose, motivo pelo qual foram submetidas à videolaparoscopia. Os sintomas clássicos mais relacionados à presença de endometriose foram analisados (dismenorréia severa ou incapacitante, dispareunia, algia pélvica acíclica, infertilidade, alterações intestinais e alterações urinárias cíclicas). Os 
sintomas da mulher com endometriose podem ser ricos, mas trabalhos anteriores já demonstraram que a intensidade dos sintomas não se correlaciona, necessariamente, com a severidade da doença (Zeyneloglu et al., 1998). Em nossa casuística, três sintomas mostraram-se relevantes e com diferença do ponto de vista estatístico: a dismenorréia severa/incapacitante, a dispareunia de profundidade e a dor acíclica. A interleucina 12 estava aumentada no fluido peritoneal de pacientes com endometriose que apresentavam as três queixas; a interleucina 18, por outro lado, apresentou-se significativamente aumentada, no sangue, na presença de dispareunia de profundidade. Avaliamos, em ambos os casos, o comportamento destes sintomas em relação à doença profunda que estava presente em 65,3\% das pacientes com dismenorréia severa/incapacitante, $62,5 \%$ das pacientes com dispareunia de profundidade e $75,8 \%$ das pacientes com dor acíclica. Estabelecemos, assim, um raciocínio: na presença de doença profunda, os sintomas anteriormente mencionados são mais prevalentes; como a doença profunda desencadeia resposta imune mais intensa, as interleucinas da via Th1 estão mais elevadas. Até o presente momento inexistem, na literatura, estudos semelhantes.

Esta foi uma vantagem em avaliarmos um grupo controle onde os sintomas de dor pélvica em suas diferentes apresentações (dismenorréia, dispareunia ou dor acíclica) ou infertilidade, considerados primordiais em mulheres com endometriose, também estivessem presentes. Desta forma, quando a análise estatística em relação aos sintomas mostrou diferença, podemos relacionar tais diferenças devido à presença da endometriose. Estudo anterior realizado em nosso meio avaliando 244 pacientes do Ambulatório de Endometriose da Clínica Ginecológica do Hospital das Clínicas da Faculdade de Medicina da Universidade de São Paulo encontrou prevalência de dismenorréia em $86 \%$ dos casos, representando a queixa mais importante; em relação às alterações intestinais, apesar de não terem sido tão freqüentes $(29,1 \%$ dos casos), apresentaram forte correlação com o acometimento intestinal nas formas de doença profunda (Neme e Abrão, 2000). 
A análise do local da doença foi realizada respeitando o critério de gravidade onde a doença profunda é considerada a mais agressiva e a forma peritoneal a mais branda. Inicialmente avaliamos se as interleucinas 12 e 18, tanto no sangue quanto no fluido peritoneal, sofriam alguma alteração na presença isolada da doença peritoneal , mas não encontramos diferenças significativas. Sendo assim, aplicamos o mesmo raciocínio para avaliar a doença profunda isoladamente e também não encontramos diferenças estatisticamente significativas.

A classificação atualmente aceita para a endometriose foi proposta em 1985 pela Sociedade Americana de Medicina Reprodutiva e revisada pela mesma entidade em 1996. Baseia-se, fundamentalmente, no tamanho dos implantes, em sua profundidade e na presença de aderências em relação ao peritônio, ovários e fundo-de-saco de Douglas. Determina quatro estadiamentos diferentes, de I a IV, com severidade crescente, baseado na somatória de pontos de achados intraoperatórios. Essa classificação é falha em não avaliar e separar formas mais graves da doença como o comprometimento dos tratos urinário e intestinal, o que foi melhor abordado por Nisolle \& Donnez, em 1997, com a proposta de dividir a endometriose em três entidades distintas (ovário, peritônio e septo-retovaginal).

Realizamos a divisão do grupo de pacientes com endometriose em relação ao estadiamento da doença agrupando-as em doença inicial (estádios I e II) e doença avançada (estádios III e IV). Em nossa casuística 28 pacientes tinham doença inicial $(38,9 \%)$ e 44 pacientes tinham doença avançada $(61,1 \%)$. A análise das dosagens de IL-12 mostrou que, no fluido peritoneal, a mesma se encontrava significativamente aumentada em pacientes com endometriose em relação ao grupo controle; no sangue esta citocina estava mais elevada em pacientes com endometriose avançada do que nas pacientes com doença inicial. Portanto, quando subdivididas segundo o estadiamento, as pacientes com endometriose avançada apresentavam dosagens séricas de IL-12 significativamente maiores que na endometriose inicial. Isso pode refletir que nas pacientes com a doença há 
realmente uma ativação imunológica visando à via de resposta celular inicial em combate ao antígeno representado pelo tecido endometrial.

Assim encontramos nesse resultado de elevação de IL-12 no fluido peritoneal um primeiro importante indício da ativação imunológica do microambiente peritoneal na doença. Entendemos que a chegada de células endometriais à cavidade pélvica desencadeia, de imediato, a resposta imune Th1.

Estudos semelhantes ao nosso foram realizados em outros meios. Zeyneloglu et al., em 1998, compararam as dosagens de IL-12 no fluido peritoneal de mulheres hígidas que seriam submetidas à laqueadura tubárea e pacientes com endometriose e não encontraram diferenças estatisticamente significantes entre os grupos estudados. Mazzeo et al. (1998) mostraram que a principal alteração relacionada à IL-12 em pacientes com endometriose era o aumento da secreção da cadeia pesada (p40) em relação à cadeia leve (p35), ressaltando que a cadeia pesada funcionaria como inibidor da própria função da IL-12, por competição direta no receptor específico, prejudicando, assim, a ativação secundária do clone NK e, conseqüentemente, a resposta Th1. Em ambos os estudos mencionados, o grupo controle era composto de pacientes que seriam submetidas à laqueadura tubárea, ou seja, sem queixas clínicas sugestivas de endometriose, como ocorria no nosso grupo controle, o que talvez possa explicar as diferenças nos resultados encontrados. Gazvani et al. (2001) também não encontraram diferenças nas dosagens de IL-12 no fluido peritoneal de pacientes com endometriose e grupo controle, nem mesmo quando comparadas as diferentes fases do ciclo menstrual. Neste estudo, diferentemente dos anteriores, o grupo controle assemelhava-se ao nosso, com pacientes submetidas à cirurgia videolaparoscópica por doenças benignas, incluindo dor abdominal, infertilidade e indicação de laqueadura tubárea; o kit de dosagem de IL-12 utilizado é que diferia do nosso (R\&D Systems, Abingdon, UK), com limite de detecção inferior ao limite que usamos $(2 \mathrm{pg} / \mathrm{mL})$. 
Nossos resultados também mostraram que as dosagens de IL-12 mostraram-se significativamente mais elevadas nos estádios avançados (III e IV) da endometriose, quando comparadas aos estádios iniciais (I e II). Associando esses achados com o mecanismo fisiopatológico da resposta imune Th1, poderíamos inferir que, quanto mais agressiva e profunda a doença, mais intenso seria o processo imunológico desencadeado por ela, de modo que isso explicaria, em parte, a elevação da IL-12. A dosagem peritoneal aumentada da IL-12 nas pacientes com endometriose em relação àquela do grupo controle, bem como níveis mais avançados da referida interleucina quanto mais agressiva a doença, demonstra-nos, claramente, que, em pacientes sem endometriose, não há a ativação imunológica da via Th1 e também que essa ativação é tão mais intensa quanto mais severo for o estímulo antigênico representado pelos focos ectópicos da doença.

A IL-18 está envolvida em ambas as respostas imunes, Th1 e Th2. Seu papel mais relevante na etiopatogenia da endometriose é o estímulo à resposta Th1; dependendo do microambiente encontrado, pode haver supressão ou inibição da resposta Th2 (Lewkowich et al., 2002). Antes de ser caracterizada como uma citocina específica, era conhecida como fator indutor do interferon-gama. Integra a superfamília da IL-1 e é secretada como pró-IL-18, sofrendo clivagem posterior na forma madura IL-18 no ambiente extracelular (Nakanishi et al., 2001). O reconhecimento inicial caracterizou-a como uma citocina pró-inflamatória, mas posteriormente foram ressaltadas diversas outras funções como a secreção de outras citocinas e angiogênese (Park et al., 2001).

Trabalhos foram publicados sobre o comportamento da IL-18 nas mulheres com endometriose. Seus resultados são conflitantes, de modo que, até o momento, não há consenso na literatura sobre a relação da IL-18 com a doença, o que nos motivou a averiguar tal situação em pacientes de nosso meio.

O trabalho de Zhang et al. (2004) encontrou menores dosagens da IL-18 peritoneal em mulheres com endometriose; por outro lado, não 
encontrou correlação entre as dosagens sérica e peritoneal desta citocina. Em outros dois trabalhos (Arici et al., 2003; Oku et al., 2004), as dosagens peritoneais de IL-18 na endometriose estavam aumentadas. Em nosso meio, Glitz (2006) não encontrou diferenças entre as dosagens sérica e peritoneal de IL-18 em pacientes com endometriose mínima. Nosso trabalho não encontrou diferenças estatisticamente significantes nas dosagens sérica ou peritoneal da IL-18 na comparação de pacientes com endometriose e grupo controle, mas tendência ao aumento de IL-18 peritoneal nos estádios avançados da doença.

Os trabalhos analisados têm algumas semelhanças e muitas diferenças, o que poderia explicar a divergência nos resultados encontrados. Novamente observamos que os grupos de pacientes estudados, quer seja o de casos ou de controles, não eram uniformes, prejudicando a comparação entre os mesmos. Arici et al. (2003) estudaram 50 pacientes com endometriose não tratada e 8 pacientes tratadas com análogos do $\mathrm{GnRH}$, comparando-as com 18 pacientes que seriam submetidas à laqueadura tubárea por via laparoscópica. Esses critérios diferiam dos nossos em relação ao uso de medicação no momento da cirurgia pelas 8 mulheres e também em relação ao grupo controle sem queixas sugestivas de endometriose. Questionamos se o uso de análogo do GnRH no momento da cirurgia não teria alterado os resultados encontrados por diminuir o processo inflamatório pélvico nessas pacientes.

Zhang et al. (2004) estudaram 44 pacientes submetidas à videolaparoscopia por doenças ginecológicas benignas, comparando-as a um grupo controle de 22 pacientes que seriam submetidas à laqueadura tubárea. Dentre as 44 pacientes do grupo de casos foram selecionadas 22 em que a endometriose foi confirmada. Esses critérios assemelharam-se aos nossos em relação ao grupo de casos, mas diferiram em relação ao grupo controle, mais uma vez assintomático em relação à endometriose. Essa, no nosso ponto de vista, seria a maior diferença entre nosso trabalho e o de Zhang et al., além da diferença no kit utilizado, podendo estar implicada na divergência dos resultados encontrados. 
Oku et al. (2004) utilizaram critérios para a inclusão nos grupos de casos e controles muito semelhantes aos nossos, sendo 39 pacientes com endometriose comprovada e 19 pacientes com outras condições ginecológicas benignas; no entanto a diferença encontrada foi que nesse estudo todas as amostras foram colhidas na fase folicular do ciclo menstrual. Dessa forma, utilizando critérios semelhantes, seus resultados diferiram dos nossos com dosagens mais elevadas de IL-18 no fluido peritoneal de pacientes com endometriose.

No estudo de Glitz (2006) foram avaliadas 34 mulheres com infertilidade e endometriose inicial no grupo de casos e 22 mulheres hígidas submetidas à laqueadura tubárea. Como os grupos eram diferentes daqueles por nós estudados, os resultados também puderam ser interpretados de maneira diferente.

A via comumente envolvida na secreção da IL-12 passa, inicialmente, pela secreção de IL-18 que, como vimos, é cofator importante para sua liberação. Nossos resultados mostraram, na avaliação das dosagens da IL18, que houve tendência ao aumento da mesma em estádios avançados da doença, não existindo diferenças nos estádios iniciais, nos quais foi encontrada a diferença anteriormente mencionada em relação à IL-12 peritoneal. Como interpretar tal discordância entre as dosagens peritoneais de IL-12 e IL-18 se assumíssemos ser um processo encadeado?

Deparamo-nos, aqui, com um conceito recente, de que nem sempre a produção de IL-12 seja dependente do estímulo de IL-18. Já se acredita que exista uma outra via de produção de IL-12, que independe do estímulo de IL18 (Morita et al., 2005). Essa, talvez, seja a via predominantemente envolvida na endometriose, explicando o porquê do aumento das dosagens de IL-12 sem modificação significativa das dosagens de IL-18.

Outra classificação baseada nos diferentes aspectos histológicos da doença foi proposta por Abrão et al. em 2003. Nela a doença foi agrupada em quatro categorias (estromal, bem-diferenciada, padrão misto de diferenciação e indiferenciada), de acordo com sua maior ou menor 
semelhança com o endométrio tópico. Tal proposta mostrou-se útil na possibilidade de predizer o padrão de comportamento da doença, sendo o padrão indiferenciado considerado como o de pior prognóstico e também o que diferenciava a evolução mais agressiva da doença. Fizemos a análise dos 72 casos em relação ao tipo histológico, sendo que 28 pacientes foram categorizadas como sem indiferenciação, ou seja, só apresentavam as formas estromal e/ou bem-diferenciada da doença, e 44 pacientes categorizadas como com indiferenciação por apresentarem as formas mista ou indiferenciada da endometriose. Após a avaliação dos dados, verificamos que, em nossa amostra, quando o estadiamento da endometriose foi correlacionado com o tipo histológico da doença, a forma avançada (estádios III e IV) apresentou maior prevalência de tipos mais indiferenciados (formas mista e indiferenciada). Consideramos que, na doença mais agressiva, tanto a evolução para estádios mais avançados é mais rápida quanto o tipo histológico já é, por natureza, mais indiferenciado e agressivo. O contrário também se revelou verdadeiro, pois a avaliação das pacientes com estádios iniciais (I e II) mostrou maiores prevalências das formas menos agressivas (estromal e bem-diferenciada).

Ao realizarmos a análise estatística da comparação das dosagens sérica e no fluido peritoneal das interleucinas 12 e 18 em relação à classificação histológica não observamos diferenças significativas. Houve, no entanto, tendência a maiores dosagens de IL-12 sérica nas pacientes com formas mais indiferenciadas da doença $(p=0,11)$. Ressaltamos, novamente, a proposta mais recente da via independente de produção da IL12. Provavelmente na doença mais agressiva e indiferenciada, possamos assumir que a ativação imunológica já seja mais intensa desde o início do processo. Isso posto, acreditamos que a elevação da IL-12 nesta forma mais agressiva pode demonstrar esse recrutamento do sistema imune tentando controlar o avanço da mesma.

De modo geral, nossos resultados mostram que a resposta Th1 (celular) está mais ativada em pacientes com endometriose e em mulheres com quadro clínico sugestivo, mas sem a doença. Algumas críticas podem 
ser feitas, fundamentalmente a respeito do tipo de grupo controle que utilizamos, que difere de outros trabalhos publicados, nos quais o que mais se encontra são mulheres que estão sendo submetidas à laqueadura tubárea por via laparoscópica. Defendemos a utilização de um grupo controle com quadro clínico semelhante e comprovadamente sem a doença, pois esta é um forma eficaz de evitarmos o viés que somente a dor crônica poderia dar na secreção das citocinas inflamatórias. Quando ambos os grupos apresentam queixas clínicas semelhantes, e os resultados mostram que a dosagem da IL-12 peritoneal é maior no grupo com endometriose, que a dosagem de IL-12 sérica eleva-se conforme o avanço da doença (estádios III e IV) e que a dosagem de IL-18 peritoneal sofre tendência a aumentar também com o avanço da doença, podemos inferir que tal diferença é decorrente da presença da própria endometriose.

Nosso trabalho pôde avaliar o comportamento da doença e da secreção das interleucinas 12 e 18 em pacientes de um grupo controle com quadro clínico sugestivo e comprovação de ausência de endometriose e nos diferentes estádios da doença. Pudemos também estudar as localizações da doença e o estadiamento da endometriose, correlacionando-os com o comportamento das citocinas referidas e em relação à fase do ciclo estudada. Incluímos, ainda, em nossa análise, a classificação histológica da endometriose, demonstrando tendência ao aumento da IL-12 sérica em pacientes com formas mais indiferenciadas da doença .

Entendemos, também, pelas diferenças de comportamento apresentadas em relação às dosagens de $\mathrm{IL}-12$ e IL-18, que na endometriose a via alternativa de secreção de IL-12 independente de IL-18 possa estar fortemente ativada.

Nenhum outro trabalho analisado fez estudo semelhante, de modo que apresentamos resultados que podem contribuir no entendimento da fisiopatologia da endometriose e auxiliar no desenvolvimento de novas técnicas diagnósticas e terapêuticas. Outros estudos se fazem necessários para que consigamos compreender, de modo definitivo, o papel imunológico, 
histológico e outros diferentes parâmetros envolvidos nesta complexa entidade globalmente conhecida como endometriose. 
CONCLUSÕES 


\section{Conclusões}

Nossos resultados permitiram concluir que:

- pacientes com endometriose apresentaram dosagens mais elevadas de Interleucina 12 no fluido peritoneal em relação às pacientes do grupo controle;

- não houve diferenças nas dosagens sérica da Interleucina 12, nem nas dosagens sérica ou no fluido peritoneal da interleucina 18 em pacientes com endometriose comparadas ao grupo controle;

- não houve diferenças em relação às dosagens de Interleucina 12 e 18 no sangue ou no fluido peritoneal em relação à fase do ciclo menstrual nas pacientes com endometriose;

- a interleucina 12 esteve aumentada no fluido peritoneal de pacientes com dismenorréia severa/incapacitante, dispareunia de profundidade e dor acíclica;

- a interleucina 18 esteve aumentada, no sangue, em pacientes com dispareunia de profundidade;

- não houve diferenças nas dosagens das interleucinas 12 e 18 ao compararmos a doença de peritônio, ovário e profunda;

- pacientes com endometriose em estádios avançados apresentaram dosagens séricas de Interleucina 12 mais elevadas em relação aos estádios iniciais da doença;

- não houve diferença em relação às dosagens de Interleucina 18 entre os estádios da doença;

- não houve diferença nas dosagens de Interleucina 12 e 18 no sangue e no fluido peritoneal em relação à classificação histológica nas pacientes com endometriose. 
ANEXOS 
Anexo A - Aprovação do Comitê de Ética e Pesquisa do HCFMUSP 
Anexo B: Termo de Consentimento pós-informação.

\section{HOSPITAL DAS CLÍNICAS \\ DA FACULDADE DE MEDICINA DA UNIVERSIDADE DE SÃO PAULO TERMO DE CONSENTIMENTO PÓS -INFORMAÇÃO}

(Obrigatório Para Pesquisas Científicas em Seres Humanos - Resolução No 01 de 13.6.1988 - CNS)

\section{I - DADOS DE IDENTIFICAÇÃO DO PACIENTE OU RESPONSÁVEL LEGAL}

1. NOME DO PACIENTE:

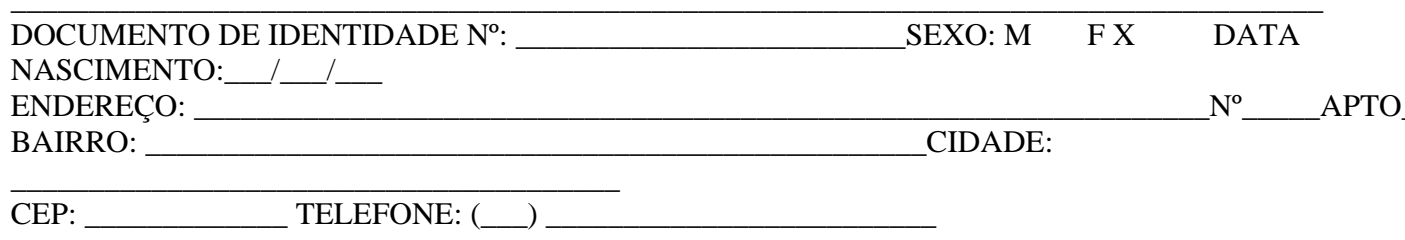

2. RESPONSÁVEL LEGAL:

NATUREZA (grau de parentesco, tutor, curador etc.): DOCUMENTO DE IDENTIDADE $\mathrm{N}^{\circ}$ NASCIMENTO:

ENDEREÇO: BAIRRO: SEXO: M F X DATA

CEP: CIDADE: $\mathrm{N}^{\circ}$ APTO

\section{II - DADOS SOBRE A PESQUISA CIENTÍFICA}

1. TÍTULO DO PROTOCOLO DE PESQUISA: Avaliação das dosagens das interleucinas 12 e 18 no sangue e no fluido peritoneal de pacientes com endometriose pélvica

2. PESQUISADOR: Flávia Fairbanks Lima de Oliveira Marino

CARGO/FUNÇÃO: Médico Pós-Graduando INSCRIÇÃO CONSELHO REGIONAL Nº: 93879

UNIDADE DO HCFMUSP: Departamento de Ginecologia
3. AVALIAÇÃO DO RISCO DA PESQUISA:
SEM RISCO
RISCO MÍNIMO
(probabilidade de que o indivíduo sofra algum dano
RISCO MÉDIO X
RISCO MAIOR

como consequência imediata ou tardia do estudo)

4. APROVAÇÃO DO PROTOCOLO DE PESQUISA PELA COMISSÃO DE ÉTICA PARA ANÁLISE DE PROJETOS DE PESQUISA- CAPPESQ/HC.

5. DURAÇÃO DA PESQUISA: .2 anos

\section{III - EXPLICAÇÕES DO PESQUISADOR AO PACIENTE OU SEU REPRESENTANTE LEGAL}

1. Justificativa e objetivos da pesquisa: para o tratamento da sua doença, a senhora terá que ser submetida a uma cirurgia. O objetivo deste estudo é avaliar se a coleta de sangue de seu braço e de líquido que existe em seu abdome no início da cirurgia pode ajudar no diagnóstico e tratamento da sua doença que se chama endometriose.

2. Procedimentos que serão utilizados e propósitos, incluindo a identificação dos procedimentos que são experimentais: conforme comentado acima, a senhora será submetida a cirurgia e também a coleta de sangue do braço e de líquido do abdômen durante esta cirurgia. 
3. Desconfortos e riscos esperados: durante a cirurgia podem ocorrer complicações, já que a senhora estará anestesiada, mas, conforme comentado, sua doença exige esta cirurgia. Todo o procedimento da pesquisa será realizado enquanto a senhora estiver anestesiada. Os desconfortos podem ocorre depois, como: dor no local da cirurgia, fraqueza, vômito (pela anestesia), infecção no corte e hematoma (mancha roxa na pele).

4. Benefícios que poderão ser obtidos: com esta pesquisa da qual a senhora está participando, tentamos descobrir se com os exames de sangue e do líquido de seu abdome poderíamos evitar a cirurgia nos casos de endometriose.

5. Procedimentos alternativos que possam ser vantajosos para o indivíduo: não há.

6. Esclarecimento sobre a garantia de receber resposta a qualquer pergunta ou esclarecimento, a qualquer dúvida acerca dos procedimentos, riscos, benefícios e outros assuntos relacionados com a pesquisa e o tratamento do indivíduo:

X Sim

Não

7. Esclarecimento sobre a liberdade de retirar seu consentimento a qualquer momento e deixar de participar no estudo, sem que isto traga prejuízo à continuação do seu cuidado e tratamento:

\section{Sim Não}

8. Compromisso sobre a segurança de que não se identificará o indivíduo e que se manterá o caráter confidencial da informação relacionada com a sua privacidade:

\section{Sim Não}

9. Compromisso de proporcionar informação atualizada obtida durante o estudo, ainda que esta possa afetar a vontade do indivíduo em continuar participando:

X Sim Não

10. Disponibilidade de assistência no HCFMUSP:

X Sim Não

11. OBSERVAÇÕES COMPLEMENTARES:

\section{IV - CONSENTIMENTO PÓS-ESCLARECIDO}

Declaro que, após ter sido convenientemente esclarecido pelo pesquisador, conforme registro nos itens 1 a 11 , do inciso III, consinto em participar, na qualidade de paciente, do Projeto de Pesquisa referido no inciso II

São Paulo, de de 20

assinatura do paciente ou responsável legal

(carimbo ou nome Legível) assinatura do pesquisador que obteve 0 consentimento

NOTA: Este termo deverá ser elaborado em duas vias, ficando uma via em poder do paciente ou seu representante legal e outra deverá ser juntada ao prontuário pelo paciente. 
Anexo C - Idade, dia do ciclo menstrual (relativo às coletas de sangue e fluido peritoneal) e quadro clínico das pacientes e controles

\begin{tabular}{|c|c|c|c|c|c|c|c|c|c|}
\hline GRUPO & Iniciais & idade & dia ciclo & dism & dispar & dor ac & infert & alt. intest & alt urin \\
\hline ENDOMETRIOSE & CFO & 37 & 5 & $\operatorname{sim}$ & não & $\operatorname{sim}$ & não & não & não \\
\hline ENDOMETRIOSE & SMM & 32 & 3 & $\operatorname{sim}$ & não & $\operatorname{sim}$ & não & $\operatorname{sim}$ & não \\
\hline ENDOMETRIOSE & FMO & 18 & 4 & $\operatorname{sim}$ & não & $\operatorname{sim}$ & não & não & não \\
\hline ENDOMETRIOSE & COM & 34 & 2 & não & não & não & $\operatorname{sim}$ & não & não \\
\hline ENDOMETRIOSE & MSQM & 26 & 9 & $\operatorname{sim}$ & $\operatorname{sim}$ & não & não & não & não \\
\hline ENDOMETRIOSE & AR & 23 & 3 & não & $\operatorname{sim}$ & não & não & não & não \\
\hline ENDOMETRIOSE & MLOC & 40 & 13 & $\operatorname{sim}$ & $\operatorname{sim}$ & $\operatorname{sim}$ & não & $\operatorname{sim}$ & não \\
\hline ENDOMETRIOSE & CAC & 27 & 10 & não & $\operatorname{sim}$ & $\operatorname{sim}$ & $\operatorname{sim}$ & $\operatorname{sim}$ & não \\
\hline ENDOMETRIOSE & SVFB & 39 & 7 & não & não & $\operatorname{sim}$ & $\operatorname{sim}$ & $\operatorname{sim}$ & não \\
\hline ENDOMETRIOSE & $\mathrm{RCA}$ & 30 & 5 & $\operatorname{sim}$ & não & não & não & não & não \\
\hline ENDOMETRIOSE & DRD & 33 & 27 & $\operatorname{sim}$ & $\operatorname{sim}$ & $\operatorname{sim}$ & $\operatorname{sim}$ & $\operatorname{sim}$ & não \\
\hline ENDOMETRIOSE & ST & 30 & 1 & não & não & $\operatorname{sim}$ & não & não & não \\
\hline ENDOMETRIOSE & LPM & 28 & 5 & $\operatorname{sim}$ & não & não & não & $\operatorname{sim}$ & não \\
\hline ENDOMETRIOSE & FCSSD & 25 & 3 & $\operatorname{sim}$ & $\operatorname{sim}$ & não & não & $\operatorname{sim}$ & não \\
\hline ENDOMETRIOSE & SAW & 29 & 16 & $\operatorname{sim}$ & não & $\operatorname{sim}$ & não & não & não \\
\hline ENDOMETRIOSE & MIRCB & 30 & 1 & não & $\operatorname{sim}$ & $\operatorname{sim}$ & não & não & não \\
\hline ENDOMETRIOSE & JCP & 25 & 13 & $\operatorname{sim}$ & $\operatorname{sim}$ & não & não & não & não \\
\hline ENDOMETRIOSE & FAG & 30 & 14 & não & $\operatorname{sim}$ & não & não & não & não \\
\hline ENDOMETRIOSE & IGS & 26 & 2 & não & não & $\operatorname{sim}$ & não & não & não \\
\hline ENDOMETRIOSE & CRNB & 39 & 9 & $\operatorname{sim}$ & $\operatorname{sim}$ & $\operatorname{sim}$ & não & $\operatorname{sim}$ & não \\
\hline ENDOMETRIOSE & VMF & 36 & 8 & não & não & não & $\operatorname{sim}$ & não & não \\
\hline ENDOMETRIOSE & APMJM & 31 & 5 & $\operatorname{sim}$ & $\operatorname{sim}$ & não & não & não & não \\
\hline ENDOMETRIOSE & FBF & 31 & 4 & não & $\operatorname{sim}$ & não & não & não & não \\
\hline ENDOMETRIOSE & PRGL & 38 & 8 & não & não & não & $\operatorname{sim}$ & não & não \\
\hline ENDOMETRIOSE & RCSS & 39 & 2 & não & não & $\operatorname{sim}$ & $\operatorname{sim}$ & não & não \\
\hline ENDOMETRIOSE & VCPS & 28 & 5 & $\operatorname{sim}$ & não & não & $\operatorname{sim}$ & não & não \\
\hline ENDOMETRIOSE & VIS & 23 & 4 & não & não & $\operatorname{sim}$ & não & não & não \\
\hline ENDOMETRIOSE & DFSR & 26 & 4 & $\operatorname{sim}$ & não & $\operatorname{sim}$ & não & $\operatorname{sim}$ & não \\
\hline ENDOMETRIOSE & TJ & 33 & 6 & não & não & não & $\operatorname{sim}$ & não & não \\
\hline ENDOMETRIOSE & BEM & 29 & 11 & $\operatorname{sim}$ & não & não & não & $\operatorname{sim}$ & $\operatorname{sim}$ \\
\hline ENDOMETRIOSE & TCB & 22 & 3 & $\operatorname{sim}$ & $\operatorname{sim}$ & $\operatorname{sim}$ & não & não & não \\
\hline ENDOMETRIOSE & MASS & 34 & 24 & $\operatorname{sim}$ & não & $\operatorname{sim}$ & não & não & não \\
\hline ENDOMETRIOSE & AESF & 37 & 2 & $\operatorname{sim}$ & $\operatorname{sim}$ & $\operatorname{sim}$ & não & $\operatorname{sim}$ & não \\
\hline ENDOMETRIOSE & RGP & 31 & 3 & $\operatorname{sim}$ & não & não & não & não & não \\
\hline ENDOMETRIOSE & CEM & 33 & 10 & $\operatorname{sim}$ & $\operatorname{sim}$ & $\operatorname{sim}$ & não & $\operatorname{sim}$ & não \\
\hline ENDOMETRIOSE & HMBV & 40 & 11 & não & $\operatorname{sim}$ & $\operatorname{sim}$ & não & $\operatorname{sim}$ & não \\
\hline ENDOMETRIOSE & MCCS & 38 & 2 & não & não & $\operatorname{sim}$ & não & não & não \\
\hline ENDOMETRIOSE & JJ & 20 & 24 & $\operatorname{sim}$ & não & não & não & não & não \\
\hline ENDOMETRIOSE & MNNS & 35 & 3 & $\operatorname{sim}$ & $\operatorname{sim}$ & não & $\operatorname{sim}$ & $\operatorname{sim}$ & não \\
\hline ENDOMETRIOSE & CMPG & 40 & 3 & $\operatorname{sim}$ & $\operatorname{sim}$ & não & $\operatorname{sim}$ & $\operatorname{sim}$ & não \\
\hline ENDOMETRIOSE & ITPS & 40 & 8 & $\operatorname{sim}$ & não & $\operatorname{sim}$ & não & não & não \\
\hline ENDOMETRIOSE & $\mathrm{HOC}$ & 37 & 26 & $\operatorname{sim}$ & não & não & não & $\operatorname{sim}$ & não \\
\hline ENDOMETRIOSE & ASF & 27 & 7 & $\operatorname{sim}$ & $\operatorname{sim}$ & $\operatorname{sim}$ & $\operatorname{sim}$ & $\operatorname{sim}$ & não \\
\hline ENDOMETRIOSE & ASS & 36 & 2 & $\operatorname{sim}$ & não & não & não & $\operatorname{sim}$ & não \\
\hline ENDOMETRIOSE & $\mathrm{CN}$ & 35 & 19 & $\operatorname{sim}$ & $\operatorname{sim}$ & $\operatorname{sim}$ & $\operatorname{sim}$ & $\operatorname{sim}$ & não \\
\hline ENDOMETRIOSE & LMJ & 37 & 17 & não & $\operatorname{sim}$ & não & $\operatorname{sim}$ & não & não \\
\hline ENDOMETRIOSE & JZP & 40 & 17 & $\operatorname{sim}$ & não & não & $\operatorname{sim}$ & $\operatorname{sim}$ & não \\
\hline
\end{tabular}




\begin{tabular}{|c|c|c|c|c|c|c|c|c|c|}
\hline GRUPO & Iniciais & idade & dia ciclo & dism & dispar & dor ac & infert & alt. intest & alt urin \\
\hline ENDOMETRIOSE & STK & 34 & 3 & não & $\operatorname{sim}$ & não & $\operatorname{sim}$ & não & não \\
\hline ENDOMETRIOSE & LGRC & 30 & 9 & $\operatorname{sim}$ & $\operatorname{sim}$ & $\operatorname{sim}$ & $\operatorname{sim}$ & $\operatorname{sim}$ & não \\
\hline ENDOMETRIOSE & CK & 33 & 6 & não & $\operatorname{sim}$ & não & não & $\operatorname{sim}$ & não \\
\hline ENDOMETRIOSE & SF & 33 & 1 & $\operatorname{sim}$ & $\operatorname{sim}$ & $\operatorname{sim}$ & não & $\operatorname{sim}$ & não \\
\hline ENDOMETRIOSE & MHTS & 39 & 9 & $\operatorname{sim}$ & $\operatorname{sim}$ & $\operatorname{sim}$ & $\operatorname{sim}$ & $\operatorname{sim}$ & não \\
\hline ENDOMETRIOSE & JGD & 36 & 3 & $\operatorname{sim}$ & não & $\operatorname{sim}$ & não & $\operatorname{sim}$ & não \\
\hline ENDOMETRIOSE & AAS & 31 & 6 & não & não & $\operatorname{sim}$ & não & $\operatorname{sim}$ & não \\
\hline ENDOMETRIOSE & $\mathrm{ECMH}$ & 36 & 2 & $\operatorname{sim}$ & $\operatorname{sim}$ & $\operatorname{sim}$ & $\operatorname{sim}$ & não & não \\
\hline ENDOMETRIOSE & EAS & 32 & 8 & $\operatorname{sim}$ & não & $\operatorname{sim}$ & não & $\operatorname{sim}$ & não \\
\hline ENDOMETRIOSE & NJM & 37 & 3 & $\operatorname{sim}$ & $\operatorname{sim}$ & sim & $\operatorname{sim}$ & sim & não \\
\hline ENDOMETRIOSE & $\mathrm{CR}$ & 31 & 6 & não & não & não & $\operatorname{sim}$ & não & não \\
\hline ENDOMETRIOSE & MSV & 33 & 22 & não & não & $\operatorname{sim}$ & não & não & não \\
\hline ENDOMETRIOSE & TG & 29 & 9 & $\operatorname{sim}$ & $\operatorname{sim}$ & $\operatorname{sim}$ & não & $\operatorname{sim}$ & não \\
\hline ENDOMETRIOSE & MAT & 35 & 1 & não & $\operatorname{sim}$ & $\operatorname{sim}$ & $\operatorname{sim}$ & $\operatorname{sim}$ & $\operatorname{sim}$ \\
\hline ENDOMETRIOSE & KNML & 29 & 4 & $\operatorname{sim}$ & não & $\operatorname{sim}$ & $\operatorname{sim}$ & $\operatorname{sim}$ & não \\
\hline ENDOMETRIOSE & SEVG & 37 & 3 & $\operatorname{sim}$ & $\operatorname{sim}$ & $\operatorname{sim}$ & não & $\operatorname{sim}$ & não \\
\hline ENDOMETRIOSE & VPSC & 24 & 5 & $\operatorname{sim}$ & não & $\operatorname{sim}$ & não & não & não \\
\hline ENDOMETRIOSE & MLRM & 36 & 8 & $\operatorname{sim}$ & $\operatorname{sim}$ & $\operatorname{sim}$ & $\operatorname{sim}$ & $\operatorname{sim}$ & não \\
\hline ENDOMETRIOSE & GF & 30 & 9 & $\operatorname{sim}$ & $\operatorname{sim}$ & $\operatorname{sim}$ & $\operatorname{sim}$ & $\operatorname{sim}$ & não \\
\hline ENDOMETRIOSE & EPAS & 35 & 8 & $\operatorname{sim}$ & $\operatorname{sim}$ & $\operatorname{sim}$ & não & não & não \\
\hline ENDOMETRIOSE & SSS & 28 & 25 & não & não & não & $\operatorname{sim}$ & $\operatorname{sim}$ & não \\
\hline ENDOMETRIOSE & AS & 29 & 2 & $\operatorname{sim}$ & $\operatorname{sim}$ & $\operatorname{sim}$ & $\operatorname{sim}$ & $\operatorname{sim}$ & não \\
\hline ENDOMETRIOSE & LQPA & 33 & 7 & $\operatorname{sim}$ & não & $\operatorname{sim}$ & não & $\operatorname{sim}$ & $\operatorname{sim}$ \\
\hline ENDOMETRIOSE & $\mathrm{ICM}$ & 30 & 7 & não & $\operatorname{sim}$ & não & não & não & não \\
\hline ENDOMETRIOSE & MPBL & 35 & 6 & $\operatorname{sim}$ & $\operatorname{sim}$ & $\operatorname{sim}$ & não & não & não \\
\hline CONTROLE & MELS & 33 & 9 & não & não & não & $\operatorname{sim}$ & não & não \\
\hline CONTROLE & EBMM & 27 & 4 & não & não & $\operatorname{sim}$ & não & não & não \\
\hline CONTROLE & LMMC & 28 & 12 & não & não & não & não & não & não \\
\hline CONTROLE & AAP & 33 & 10 & não & não & não & não & não & não \\
\hline CONTROLE & SCM & 30 & 4 & $\operatorname{sim}$ & $\operatorname{sim}$ & não & não & não & não \\
\hline CONTROLE & ETS & 29 & 8 & não & não & não & $\operatorname{sim}$ & não & não \\
\hline CONTROLE & PSS & 24 & 19 & não & não & $\operatorname{sim}$ & $\operatorname{sim}$ & $\operatorname{sim}$ & não \\
\hline CONTROLE & MPMF & 37 & 7 & não & $\operatorname{sim}$ & $\operatorname{sim}$ & não & não & não \\
\hline CONTROLE & LFM & 38 & 26 & não & não & $\operatorname{sim}$ & não & não & não \\
\hline CONTROLE & MHBC & 40 & 9 & não & não & não & não & não & não \\
\hline CONTROLE & FGBM & 36 & 4 & não & $\operatorname{sim}$ & $\operatorname{sim}$ & não & não & não \\
\hline CONTROLE & LAS & 36 & 5 & não & não & $\operatorname{sim}$ & não & $\operatorname{sim}$ & não \\
\hline CONTROLE & NQM & 34 & 2 & não & não & $\operatorname{sim}$ & não & não & não \\
\hline CONTROLE & SRRBS & 36 & 26 & não & não & não & não & não & não \\
\hline CONTROLE & VHS & 28 & 5 & não & não & não & não & não & não \\
\hline CONTROLE & RGC & 38 & 5 & não & não & não & não & não & não \\
\hline CONTROLE & MLC & 28 & 3 & não & não & não & não & não & não \\
\hline CONTROLE & RSA & 37 & 1 & não & não & sim & não & não & não \\
\hline CONTROLE & LRSC & 40 & 9 & sim & sim & sim & não & não & não \\
\hline CONTROLE & $\mathrm{JMX}$ & 36 & 21 & não & não & não & sim & não & não \\
\hline CONTROLE & ACVB & 32 & 10 & não & não & não & não & não & não \\
\hline CONTROLE & PLS & 27 & 10 & não & $\operatorname{sim}$ & não & não & não & não \\
\hline CONTROLE & MSM & 40 & 2 & $\operatorname{sim}$ & $\operatorname{sim}$ & $\operatorname{sim}$ & não & não & não \\
\hline CONTROLE & CARS & 37 & 27 & não & não & não & $\operatorname{sim}$ & não & não \\
\hline CONTROLE & AMSS & 32 & 15 & $\operatorname{sim}$ & $\operatorname{sim}$ & não & não & não & não \\
\hline
\end{tabular}




$\begin{array}{lccccccccc}\text { GRUPO } & \text { Iniciais } & \text { idade } & \text { dia ciclo } & \text { dism } & \text { dispar } & \text { dor ac } & \text { infert } & \text { alt. intest } & \text { alt urin } \\ \text { CONTROLE } & \text { MSS } & 39 & 28 & \text { sim } & \text { sim } & \text { não } & \text { não } & \text { não } & \text { não } \\ \text { CONTROLE } & \text { DPS } & 21 & 17 & \operatorname{sim} & \operatorname{sim} & \text { não } & \text { sim } & \text { não } & \text { não } \\ \text { CONTROLE } & \text { MBA } & 26 & 6 & \text { sim } & \text { não } & \text { não } & \text { não } & \text { não } & \text { não } \\ \text { CONTROLE } & \text { TRCJ } & 34 & 5 & \text { não } & \text { não } & \text { sim } & \text { não } & \text { não } & \text { não } \\ \text { CONTROLE } & \text { YT } & 38 & 3 & \text { sim } & \text { sim } & \text { sim } & \text { sim } & \text { não } & \text { não } \\ \text { CONTROLE } & \text { JAS } & 29 & 3 & \text { não } & \text { sim } & \text { não } & \text { não } & \text { não } & \text { não } \\ \text { CONTROLE } & \text { MAS } & 34 & 8 & \text { sim } & \text { sim } & \text { sim } & \text { sim } & \text { não } & \text { não } \\ \text { CONTROLE } & \text { EGMA } & 27 & 5 & \text { não } & \text { não } & \text { não } & \text { sim } & \text { não } & \text { não }\end{array}$

Legenda: dism - dismenorréia severa/incapacitante, dispar - dispareunia de profundidade, dor ac - dor acíclica, infert - infertilidade, alt. instest alterações intestinais cíclicas, alt. urin - alterações urinárias cíclicas 
Anexo D - Estadiamento, local da doença e classificação histológica

\begin{tabular}{|c|c|c|c|c|c|c|}
\hline GRUPO & Iniciais & estadio & peritônio & ovário & profunda & tipo histol \\
\hline ENDOMETRIOSE & CFO & 1 & $\operatorname{sim}$ & não & não & E \\
\hline ENDOMETRIOSE & SMM & 1 & $\operatorname{sim}$ & não & não & $E+M$ \\
\hline ENDOMETRIOSE & FMO & 1 & não & $\operatorname{sim}$ & não & $E+B D$ \\
\hline ENDOMETRIOSE & COM & 1 & $\operatorname{sim}$ & não & não & BD \\
\hline ENDOMETRIOSE & MSQM & 1 & $\operatorname{sim}$ & não & não & $E+B D$ \\
\hline ENDOMETRIOSE & AR & 1 & $\operatorname{sim}$ & não & não & $E+B D$ \\
\hline ENDOMETRIOSE & MLOC & 1 & $\operatorname{sim}$ & não & não & $E+M$ \\
\hline ENDOMETRIOSE & CAC & 1 & $\operatorname{sim}$ & não & não & $E+M$ \\
\hline ENDOMETRIOSE & SVFB & 1 & $\operatorname{sim}$ & não & não & $E+M$ \\
\hline ENDOMETRIOSE & RCA & 2 & não & $\operatorname{sim}$ & não & $E+I$ \\
\hline ENDOMETRIOSE & DRD & 2 & $\operatorname{sim}$ & $\operatorname{sim}$ & não & $E+M$ \\
\hline ENDOMETRIOSE & ST & 2 & não & $\operatorname{sim}$ & não & $E+B D$ \\
\hline ENDOMETRIOSE & LPM & 2 & $\operatorname{sim}$ & $\operatorname{sim}$ & não & $E+M$ \\
\hline ENDOMETRIOSE & FCSSD & 2 & não & $\operatorname{sim}$ & não & $E+B D$ \\
\hline ENDOMETRIOSE & SAW & 2 & não & $\operatorname{sim}$ & não & E \\
\hline ENDOMETRIOSE & MIRCB & 2 & $\operatorname{sim}$ & não & $\operatorname{sim}$ & $E+1$ \\
\hline ENDOMETRIOSE & JCP & 2 & não & $\operatorname{sim}$ & não & $E+B D$ \\
\hline ENDOMETRIOSE & FAG & 2 & $\operatorname{sim}$ & não & não & E \\
\hline ENDOMETRIOSE & IGS & 2 & não & $\operatorname{sim}$ & não & $E+B D$ \\
\hline ENDOMETRIOSE & CRNB & 2 & não & $\operatorname{sim}$ & não & $E$ \\
\hline ENDOMETRIOSE & VMF & 2 & $\operatorname{sim}$ & não & não & $E+B D$ \\
\hline ENDOMETRIOSE & APMJM & 2 & $\operatorname{sim}$ & não & não & $E+B D$ \\
\hline ENDOMETRIOSE & FBF & 2 & $\operatorname{sim}$ & $\operatorname{sim}$ & não & $E+B D$ \\
\hline ENDOMETRIOSE & PRGL & 2 & não & $\operatorname{sim}$ & não & $E+B D$ \\
\hline ENDOMETRIOSE & RCSS & 2 & não & $\operatorname{sim}$ & não & $E+M$ \\
\hline ENDOMETRIOSE & VCPS & 2 & não & $\operatorname{sim}$ & não & $E+B D$ \\
\hline ENDOMETRIOSE & VIS & 2 & não & $\operatorname{sim}$ & não & $E+M$ \\
\hline ENDOMETRIOSE & DFSR & 2 & $\operatorname{sim}$ & não & $\operatorname{sim}$ & $E+B D$ \\
\hline ENDOMETRIOSE & TJ & 3 & $\operatorname{sim}$ & não & $\operatorname{sim}$ & $E+M$ \\
\hline ENDOMETRIOSE & BEM & 3 & não & $\operatorname{sim}$ & não & $E+M$ \\
\hline ENDOMETRIOSE & TCB & 3 & não & $\operatorname{sim}$ & não & $E+M$ \\
\hline ENDOMETRIOSE & MASS & 3 & $\operatorname{sim}$ & $\operatorname{sim}$ & não & $E+M$ \\
\hline ENDOMETRIOSE & AESF & 3 & $\operatorname{sim}$ & $\operatorname{sim}$ & $\operatorname{sim}$ & $E+B D$ \\
\hline ENDOMETRIOSE & RGP & 4 & $\operatorname{sim}$ & $\operatorname{sim}$ & $\operatorname{sim}$ & $E+M$ \\
\hline ENDOMETRIOSE & CEM & 4 & não & $\operatorname{sim}$ & $\operatorname{sim}$ & $E+B D$ \\
\hline ENDOMETRIOSE & HMBV & 4 & não & $\operatorname{sim}$ & $\operatorname{sim}$ & $E+I$ \\
\hline ENDOMETRIOSE & MCCS & 4 & não & $\operatorname{sim}$ & $\operatorname{sim}$ & $E+M$ \\
\hline ENDOMETRIOSE & JJ & 4 & $\operatorname{sim}$ & $\operatorname{sim}$ & $\operatorname{sim}$ & $E+I$ \\
\hline ENDOMETRIOSE & MNNS & 4 & não & não & $\operatorname{sim}$ & $E+M$ \\
\hline ENDOMETRIOSE & CMPG & 4 & não & $\operatorname{sim}$ & $\operatorname{sim}$ & $E+M$ \\
\hline ENDOMETRIOSE & ITPS & 4 & não & $\operatorname{sim}$ & $\operatorname{sim}$ & $E+B D$ \\
\hline ENDOMETRIOSE & $\mathrm{HOC}$ & 4 & não & não & $\operatorname{sim}$ & $E+B D$ \\
\hline ENDOMETRIOSE & ASF & 4 & não & $\operatorname{sim}$ & $\operatorname{sim}$ & $E+M$ \\
\hline ENDOMETRIOSE & ASS & 4 & $\operatorname{sim}$ & $\operatorname{sim}$ & não & $E+M$ \\
\hline ENDOMETRIOSE & $\mathrm{CN}$ & 4 & não & $\operatorname{sim}$ & $\operatorname{sim}$ & $E+M$ \\
\hline ENDOMETRIOSE & LMJ & 4 & $\operatorname{sim}$ & $\operatorname{sim}$ & $\operatorname{sim}$ & $E+M$ \\
\hline ENDOMETRIOSE & JZP & 4 & $\operatorname{sim}$ & $\operatorname{sim}$ & $\operatorname{sim}$ & $E+M$ \\
\hline ENDOMETRIOSE & STK & 4 & não & $\operatorname{sim}$ & $\operatorname{sim}$ & $E+M$ \\
\hline ENDOMETRIOSE & LGRC & 4 & $\operatorname{sim}$ & $\operatorname{sim}$ & $\operatorname{sim}$ & $E+M$ \\
\hline
\end{tabular}




\begin{tabular}{|c|c|c|c|c|c|c|}
\hline GRUPO & Iniciais & estadio & peritônio & ovário & profunda & tipo histol \\
\hline ENDOMETRIOSE & CK & 4 & não & não & $\operatorname{sim}$ & $E+M$ \\
\hline ENDOMETRIOSE & SF & 4 & $\operatorname{sim}$ & $\operatorname{sim}$ & $\operatorname{sim}$ & $E+M$ \\
\hline ENDOMETRIOSE & MHTS & 4 & não & não & $\operatorname{sim}$ & $E+M$ \\
\hline ENDOMETRIOSE & JGD & 4 & não & não & $\operatorname{sim}$ & $E+M$ \\
\hline ENDOMETRIOSE & AAS & 4 & não & não & $\operatorname{sim}$ & $E+M$ \\
\hline ENDOMETRIOSE & $\mathrm{ECMH}$ & 4 & não & $\operatorname{sim}$ & $\operatorname{sim}$ & $E+M$ \\
\hline ENDOMETRIOSE & EAS & 4 & não & $\operatorname{sim}$ & $\operatorname{sim}$ & $E+B D$ \\
\hline ENDOMETRIOSE & NJM & 4 & $\operatorname{sim}$ & $\operatorname{sim}$ & $\operatorname{sim}$ & $E+M$ \\
\hline ENDOMETRIOSE & CR & 4 & não & não & $\operatorname{sim}$ & $E+M$ \\
\hline ENDOMETRIOSE & MSV & 4 & $\operatorname{sim}$ & $\operatorname{sim}$ & $\operatorname{sim}$ & $E+B D$ \\
\hline ENDOMETRIOSE & TG & 4 & $\operatorname{sim}$ & não & $\operatorname{sim}$ & $E+M$ \\
\hline ENDOMETRIOSE & MAT & 4 & não & não & $\operatorname{sim}$ & $E+M$ \\
\hline ENDOMETRIOSE & KNML & 4 & não & $\operatorname{sim}$ & $\operatorname{sim}$ & $E+M$ \\
\hline ENDOMETRIOSE & SEVG & 4 & não & não & $\operatorname{sim}$ & $E+M$ \\
\hline ENDOMETRIOSE & VPSC & 2 & $\operatorname{sim}$ & não & não & $E+B D$ \\
\hline ENDOMETRIOSE & MLRM & 2 & $\operatorname{sim}$ & não & não & $E+B D$ \\
\hline ENDOMETRIOSE & GF & 2 & não & $\operatorname{sim}$ & não & $E+M$ \\
\hline ENDOMETRIOSE & EPAS & 2 & não & não & $\operatorname{sim}$ & $E+M$ \\
\hline ENDOMETRIOSE & SSS & 2 & $\operatorname{sim}$ & não & não & $E+B D$ \\
\hline ENDOMETRIOSE & AS & 2 & não & não & $\operatorname{sim}$ & $E+M$ \\
\hline ENDOMETRIOSE & LQPA & 2 & não & $\operatorname{sim}$ & não & $E+B D$ \\
\hline ENDOMETRIOSE & ICM & 2 & não & não & $\operatorname{sim}$ & $E+M$ \\
\hline ENDOMETRIOSE & MPBL & 2 & $\operatorname{sim}$ & não & não & $\mathrm{BD}$ \\
\hline CONTROLE & MELS & na & na & na & na & na \\
\hline CONTROLE & EBMM & na & na & na & na & na \\
\hline CONTROLE & LMMC & na & na & na & na & na \\
\hline CONTROLE & AAP & na & na & na & na & na \\
\hline CONTROLE & SCM & na & na & na & na & na \\
\hline CONTROLE & ETS & na & na & na & na & na \\
\hline CONTROLE & PSS & na & na & na & na & na \\
\hline CONTROLE & MPMF & na & na & na & na & na \\
\hline CONTROLE & LFM & na & na & na & na & na \\
\hline CONTROLE & MHBC & na & na & na & na & na \\
\hline CONTROLE & FGBM & na & na & na & na & na \\
\hline CONTROLE & LAS & na & na & na & na & na \\
\hline CONTROLE & NQM & na & na & na & na & na \\
\hline CONTROLE & SRRBS & na & na & na & na & na \\
\hline CONTROLE & VHS & na & na & na & na & na \\
\hline CONTROLE & RGC & na & na & na & na & na \\
\hline CONTROLE & MLC & na & na & na & na & na \\
\hline CONTROLE & RSA & na & na & na & na & na \\
\hline CONTROLE & LRSC & na & na & na & na & na \\
\hline CONTROLE & JMX & na & na & na & na & na \\
\hline CONTROLE & ACVB & na & na & na & na & na \\
\hline CONTROLE & PLS & na & na & na & na & na \\
\hline CONTROLE & MSM & na & na & na & na & na \\
\hline CONTROLE & CARS & na & na & na & na & na \\
\hline CONTROLE & AMSS & na & na & na & na & na \\
\hline CONTROLE & MSS & na & na & na & na & na \\
\hline CONTROLE & DPS & na & na & na & na & na \\
\hline
\end{tabular}




$\begin{array}{lcccccc}\text { GRUPO } & \text { Iniciais } & \text { estadio } & \text { peritônio } & \text { ovário } & \text { profunda } & \text { tipo histol } \\ \text { CONTROLE } & \text { MBA } & \text { na } & \text { na } & \text { na } & \text { na } & \text { na } \\ \text { CONTROLE } & \text { TRCJ } & \text { na } & \text { na } & \text { na } & \text { na } & \text { na } \\ \text { CONTROLE } & \text { YT } & \text { na } & \text { na } & \text { na } & \text { na } & \text { na } \\ \text { CONTROLE } & \text { JAS } & \text { na } & \text { na } & \text { na } & \text { na } & \text { na } \\ \text { CONTROLE } & \text { MAS } & \text { na } & \text { na } & \text { na } & \text { na } & \text { na } \\ \text { CONTROLE } & \text { EGMA } & \text { na } & \text { na } & \text { na } & \text { na } & \text { na }\end{array}$

Legenda: tipo histol - tipo histológico, E - padrão estromal, BD - padrão bem diferenciado, M - padrão misto, I - padrão indiferenciado (classificação descrita na seção Pacientes e Métodos), na - não se aplica 
Anexo E - Dosagens das IL 12 e IL 18 no sangue e fluido peritoneal

\begin{tabular}{|c|c|c|c|c|c|}
\hline GRUPO & Iniciais & IL12 FP & IL18 FP & IL12 sg & IL18 sg \\
\hline ENDOMETRIOSE & CFO & 25,503 & 73,284 & 41 & 17,139 \\
\hline ENDOMETRIOSE & SMM & 93,744 & 31,914 & 63,01 & 19,503 \\
\hline ENDOMETRIOSE & FMO & 44,443 & 30,732 & 36,82 & 8,274 \\
\hline ENDOMETRIOSE & COM & 138,032 & 15,366 & 31,8 & 12,411 \\
\hline ENDOMETRIOSE & MSQM & 25,781 & 254,13 & 204 & 30,732 \\
\hline ENDOMETRIOSE & AR & 35,251 & 85,104 & 100,6 & 23,049 \\
\hline ENDOMETRIOSE & MLOC & 70,531 & 412,704 & 24,755 & 51,588 \\
\hline ENDOMETRIOSE & CAC & 195,076 & 101,891 & 79,604 & 114,64 \\
\hline ENDOMETRIOSE & SVFB & aus & aus & 57,747 & 78,587 \\
\hline ENDOMETRIOSE & RCA & 61,155 & 53,781 & 61,89 & 23,049 \\
\hline ENDOMETRIOSE & DRD & aus & aus & 31,08 & 39,096 \\
\hline ENDOMETRIOSE & ST & 299,027 & 33,096 & 56,32 & 27,186 \\
\hline ENDOMETRIOSE & LPM & 26,617 & 43,143 & 32,64 & 33,687 \\
\hline ENDOMETRIOSE & FCSSD & 42,772 & 27,186 & 31,52 & 11,82 \\
\hline ENDOMETRIOSE & SAW & 50,97 & 46,566 & 25,39 & 18,321 \\
\hline ENDOMETRIOSE & MIRCB & 56,977 & 26,595 & 30,69 & 73,875 \\
\hline ENDOMETRIOSE & JCP & 38,594 & 61,464 & 29,29 & 28,959 \\
\hline ENDOMETRIOSE & FAG & 114,635 & 72,693 & 63,56 & 23,64 \\
\hline ENDOMETRIOSE & IGS & 30,795 & 43,143 & 61,34 & 34,869 \\
\hline ENDOMETRIOSE & CRNB & 28,845 & 105,198 & 39,05 & 36,642 \\
\hline ENDOMETRIOSE & VMF & 33,21 & 39,098 & 79,45 & 25,413 \\
\hline ENDOMETRIOSE & APMJM & 236,729 & 461,426 & 39,601 & 103,176 \\
\hline ENDOMETRIOSE & FBF & 107,88 & 91,97 & 85,79 & 279,435 \\
\hline ENDOMETRIOSE & PRGL & 49,499 & 454,261 & 112,184 & 51,588 \\
\hline ENDOMETRIOSE & RCSS & aus & aus & 109,709 & 51,588 \\
\hline ENDOMETRIOSE & VCPS & 105,173 & 353,951 & 41,663 & 38,691 \\
\hline ENDOMETRIOSE & VIS & 119,67 & 156,89 & 357,149 & 93,145 \\
\hline ENDOMETRIOSE & DFSR & 176,84 & 97,06 & 369,522 & 143,3 \\
\hline ENDOMETRIOSE & TJ & 52,799 & 18,321 & 118,2 & 11,229 \\
\hline ENDOMETRIOSE & BEM & 80,016 & 288,033 & 78,89 & 42,99 \\
\hline ENDOMETRIOSE & TCB & 28,879 & 1114,874 & 101,874 & 103,176 \\
\hline ENDOMETRIOSE & MASS & 199,05 & 201,4 & 358,387 & 279,435 \\
\hline ENDOMETRIOSE & AESF & aus & aus & 104,76 & 37,258 \\
\hline ENDOMETRIOSE & RGP & 24,945 & 56,736 & 70,53 & 20,094 \\
\hline ENDOMETRIOSE & CEM & 132,461 & 33,687 & 51,86 & 2,955 \\
\hline ENDOMETRIOSE & HMBV & 32,466 & 43,734 & 33,47 & 7,092 \\
\hline ENDOMETRIOSE & MCCS & 36,366 & 30,141 & 161,4 & 4,728 \\
\hline ENDOMETRIOSE & JJ & 34,416 & 80,967 & 78,33 & 27,186 \\
\hline ENDOMETRIOSE & MNNS & aus & aus & 25,39 & 23,049 \\
\hline ENDOMETRIOSE & CMPG & 20,489 & 24,231 & 37,1 & 17,139 \\
\hline ENDOMETRIOSE & ITPS & 33,302 & 26,595 & 24,56 & 9,456 \\
\hline ENDOMETRIOSE & $\mathrm{HOC}$ & 36,505 & 269,496 & 185,6 & 16,548 \\
\hline ENDOMETRIOSE & ASF & 29,681 & 41,961 & 55,48 & 4,137 \\
\hline ENDOMETRIOSE & ASS & 85,388 & 24,822 & 204,5 & 17,73 \\
\hline ENDOMETRIOSE & $\mathrm{CN}$ & 28,566 & 106,38 & 182 & 26,595 \\
\hline ENDOMETRIOSE & LMJ & 98,45 & 79,26 & 108,75 & 21,9 \\
\hline ENDOMETRIOSE & JZP & 51,685 & 81,558 & 136,7 & 26,595 \\
\hline ENDOMETRIOSE & STK & 32,745 & 151,887 & 234,6 & 15,366 \\
\hline
\end{tabular}




\begin{tabular}{|c|c|c|c|c|c|}
\hline GRUPO & Iniciais & IL12 FP & IL18 FP & IL12 sg & IL18 sg \\
\hline ENDOMETRIOSE & LGRC & 51,964 & 63,828 & 42,95 & 13,002 \\
\hline ENDOMETRIOSE & CK & 16,507 & 717,933 & 46,2 & 38,691 \\
\hline ENDOMETRIOSE & SF & 18,981 & 133,269 & 28,466 & 21,495 \\
\hline ENDOMETRIOSE & MHTS & 75,068 & 217,816 & 87,44 & 77,382 \\
\hline ENDOMETRIOSE & JGD & aus & aus & 81,666 & 471,457 \\
\hline ENDOMETRIOSE & AAS & 24,342 & 502,983 & 185,178 & 98,877 \\
\hline ENDOMETRIOSE & $\mathrm{ECMH}$ & aus & aus & 419,834 & 81,681 \\
\hline ENDOMETRIOSE & EAS & 75,48 & 505,849 & 376,532 & 98,877 \\
\hline ENDOMETRIOSE & NJM & 65,17 & 103,176 & 68,882 & 53,021 \\
\hline ENDOMETRIOSE & $\mathrm{CR}$ & aus & aus & 104,348 & 140,434 \\
\hline ENDOMETRIOSE & MSV & 126,618 & 288,033 & 85,378 & 42,99 \\
\hline ENDOMETRIOSE & TG & 97,337 & 454,261 & 32,59 & 51,588 \\
\hline ENDOMETRIOSE & MAT & 681,709 & 133,269 & 190,952 & 21,495 \\
\hline ENDOMETRIOSE & KNML & 493,242 & 342,487 & 619,436 & 110,341 \\
\hline ENDOMETRIOSE & SEVG & 143,938 & 217,816 & 472,29 & 77,382 \\
\hline ENDOMETRIOSE & VPSC & 10,733 & 90,279 & 21,455 & 455,694 \\
\hline ENDOMETRIOSE & MLRM & 17,59 & 83,29 & 171,569 & 75,949 \\
\hline ENDOMETRIOSE & GF & 164,146 & 289,466 & 882,135 & 80,248 \\
\hline ENDOMETRIOSE & EPAS & 299,413 & 181,991 & 581,495 & 30,093 \\
\hline ENDOMETRIOSE & SSS & 111,771 & 48,722 & 440,042 & 100,31 \\
\hline ENDOMETRIOSE & AS & 823,987 & 163,362 & 112,184 & 73,083 \\
\hline ENDOMETRIOSE & LQPA & 501,23 & 324,82 & 337,354 & 167,661 \\
\hline ENDOMETRIOSE & $\mathrm{ICM}$ & 67,99 & 65,918 & 986,06 & 81,681 \\
\hline ENDOMETRIOSE & MPBL & 93,74 & 65,918 & 34,652 & 458,56 \\
\hline CONTROLE & MELS & 12,383 & 32,505 & 46,2 & 10,047 \\
\hline CONTROLE & EBMM & 3,722 & 112,29 & 12,27 & 13,002 \\
\hline CONTROLE & LMMC & 20,51 & 72,102 & 32,89 & 20,094 \\
\hline CONTROLE & AAP & 94,75 & 67,965 & 53,72 & 13,002 \\
\hline CONTROLE & SCM & 97,45 & 137,703 & 24,62 & 59,1 \\
\hline CONTROLE & ETS & 65,88 & 63,237 & 51,561 & 134,157 \\
\hline CONTROLE & PSS & 19,36 & 39,006 & 63,108 & 11,229 \\
\hline CONTROLE & MPMF & 38,9 & 96,43 & 232,605 & 7,092 \\
\hline CONTROLE & LFM & 0 & 41,37 & 48,674 & 11,229 \\
\hline CONTROLE & MHBC & 83,05 & 67,53 & 8,671 & 26,595 \\
\hline CONTROLE & FGBM & 212,98 & 398,06 & 427,258 & 18,321 \\
\hline CONTROLE & LAS & 18,569 & 80,967 & 87,44 & 41,37 \\
\hline CONTROLE & NQM & 18,94 & 33,97 & 23,517 & 23,64 \\
\hline CONTROLE & SRRBS & 73,82 & 50,48 & 56,097 & 19,503 \\
\hline CONTROLE & VHS & 6,609 & 65,01 & 65,89 & 24,231 \\
\hline CONTROLE & RGC & 48,93 & 78,52 & 37,539 & 74,516 \\
\hline CONTROLE & MLC & 67,1 & 52,85 & 7,021 & 37,258 \\
\hline CONTROLE & RSA & 179,405 & 342,487 & 225,181 & 110,341 \\
\hline CONTROLE & LRSC & 62,95 & 454,261 & 86,202 & 93,145 \\
\hline CONTROLE & $\mathrm{JMX}$ & 257 & 312,97 & 107,235 & 143,3 \\
\hline CONTROLE & ACVB & 26,404 & 349,652 & 37,127 & 114,64 \\
\hline CONTROLE & PLS & 214,871 & 298,064 & 101,049 & 41,557 \\
\hline CONTROLE & MSM & 23,76 & 0 & 114,246 & 68,784 \\
\hline CONTROLE & CARS & 34,652 & 214,95 & 81,666 & 50,155 \\
\hline CONTROLE & AMSS & 67,9 & 65,99 & 226,419 & 108,908 \\
\hline CONTROLE & MSS & 76,34 & 89,03 & 29,703 & 116,073 \\
\hline CONTROLE & DPS & 3,31 & 214,95 & 42,9 & 180,558 \\
\hline
\end{tabular}




$\begin{array}{lccccc}\text { GRUPO } & \text { Iniciais } & \text { IL12 FP } & \text { IL18 FP } & \text { IL12 sg } & \text { IL18 sg } \\ \text { CONTROLE } & \text { MBA } & 12,383 & 181,991 & 63,933 & 54,454 \\ \text { CONTROLE } & \text { TRCJ } & 89,01 & 104,57 & 119,194 & 54,454 \\ \text { CONTROLE } & \text { YT } & 77,13 & 197,13 & 49,499 & 118,939 \\ \text { CONTROLE } & \text { JAS } & 123,31 & 208,93 & 426,433 & 100,31 \\ \text { CONTROLE } & \text { MAS } & 209,923 & 772,387 & 165,383 & 74,516 \\ \text { CONTROLE } & \text { EGMA } & 83,316 & 42,99 & 218,171 & 71,65\end{array}$

Legenda: FP - fluido peritoneal, sg - sangue, aus - fluido peritoneal ausente 
"A concentração da interleucina 12 está aumentada em pacientes com endometriose e se correlaciona com a severidade da doenca"

INTRODUCÃO

A endometriose caracteriza-se pelo implante, crescimento e desenvolvimento de tecido endometrial em localização extra-uterina (D'Hooghe et al., 2003). Acomete cerca de $10 \%$ da população feminina na menacme (Missmer \& Cramer, 2003) e sua a etiopatogenia exata permanece desconhecida (Berkanoglu \& Arici, 2003). Com o conhecimento mais profundo dos mecanismos imunológicos envolvidos no reconhecimento de antígenos e sabendo que o tecido endometrial na cavidade peritoneal funcionava como tal, houve espaço para a investigação de diversos aspectos envolvidos no processo, principalmente o papel das diversas citocinas, fatores de crescimento e angiogênicos e também papel de células diretamente relacionadas como as células natural-killer e macrófagos peritoneais (Harada et al., 2001; Pasoto et al., 2005; Dias Jr et al., 2006).

Aceita-se, atualmente, que as interleucinas $1,4,5,6,8,10$, fator de necrose tumoral alfa (TNF- $\alpha$ ) e fator endotelial de crescimento vascular (VEGF) estejam aumentadas na endometriose (Harada et al., 2001; Podgaec et al., 2007). A interleucina 12 (IL-12) tem como principais funções biológicas a indução da transcrição e secreção de outras citocinas, principalmente o interferon-gama (IFN-y); aumento da citotoxicidade bem como indução da proliferação das células natural-killer (D'Andrea et al., 1992). Por todas essas características e funções é considerada uma 
molécula-chave do sistema imune determinando a conversão das células $T$ primordiais para o padrão Th1 (Gazvani et al., 2001).

Gallinelli et al. (2004) demonstraram aumento dos níveis de IL-12 no fluido peritoneal das pacientes com endometriose estádios III ou IV, mas Gazvani et al. (2001) não encontraram diferenças na comparação das dosagens de IL-12 nos diversos estádios da doença, nas diferentes fases do ciclo menstrual ou em relação às queixas de dismenorréia, infertilidade ou dor pélvica crônica.

A interleucina 18 (IL-18) participa ativamente na a produção do interferon-gama e, conseqüentemente, ativando a proliferação dos clones celulares de linfócitos $\mathrm{T}$ e células NK, além de estimular a liberação de diversas citocinas como IL-4, 5, 10 e 13, além de estimular a produção de angiopoetina 2 e fatores vasculares locais (Zhang et al., 2004). É necessária em doses fisiológicas para os processos de implantação embrionária (Chaouat et al., 2002), mas, em doses elevadas está implicada nos abortamentos de repetição (Lédée-Bataille et al., 2005). Suas funções biológicas principais são a indução da produção e secreção do interferongama, indução da produção de IL-12 e TNF-alfa e liberação das citocinas do braço Th2 (Gracie et al, 2003).

Inicialmente demonstrou-se que a IL-18 do fluido peritoneal estaria mais elevada em pacientes com endometriose do que em mulheres saudáveis (Arici et al., 2003), no entanto outro estudo mostrou resultados bastante discordantes com os anteriores com dosagens inferiores da IL-18 peritoneal em pacientes com endometriose (Zhang et al., 2004).

Conforme salientado, há incertezas sobre a etiopatogenia da endometriose, principalmente no âmbito da imunidade. Neste quesito as interleucinas 12 e 18 têm papel importante por atuarem como desencadeadoras da resposta imune Th1 a partir de estímulos sobre os linfócitos Th0 (D’Andrea et al., 1992; Gazvani et al., 2001). Adicionalmente os dados são conflitantes sobre a participação destas interleucinas na endometriose pélvica. Este estudo foi realizado visando aprofundar os 
conhecimentos sobre algumas dúvidas acerca da participação das interleucinas 12 e 18 em pacientes com endometriose pélvica.

\section{PACIENTES E MÉTODOS}

Este estudo foi aprovado pelo Comitê de Ética do Hospital das Clínicas da Faculdade de Medicina da Universidade de São Paulo, onde foram avaliadas 105 pacientes no Setor de Endometriose da Clínica Ginecológica deste hospital no período de fevereiro de 2004 a dezembro de 2005. Todas apresentavam quadro clínico sugestivo de endometriose, representado pelas queixas clínicas de dismenorréia severa ou incapacitante, dispareunia de profundidade, algia pélvica crônica, infertilidade, alterações urinárias (dor e/ou sangramento) ou intestinais cíclicas (dor e/ou sangramento) e, por esse motivo, foram submetidas à videolaparoscopia.

Foram adotados como critério de inclusão idade entre 18 e 40 anos, ciclos menstruais eumenorreicos, ausência de doenças auto-imunes e nãoutilização de medicamentos hormonais nos 3 meses que antecederam a cirurgia. Os critérios de exclusão foram ausência de líquido peritoneal durante o procedimento laparoscópico e co-existência de outros fatores causadores de infertilidade.

Avaliamos ainda a fase do ciclo em que se encontrava a paciente no momento da videolaparoscopia (fases folicular e lútea).

As pacientes do grupo com endometriose foram estadiadas segundo a classificação da American Society for Reproductive Medicine (1996). Agrupamos os estádios I e II como "estádios iniciais" e os estádios III e IV como "estádios avançados"; 28 pacientes foram classificadas como estádios iniciais e 44 pacientes como estádios avançados.

Estudamos também a localização mais importante da doença, usando um critério de severidade do órgão acometido. Estabelecemos três categorias : doença peritoneal, ovariana e doença profunda, a qual englobava o acometimento retrocervical (lesões profundas, com mais que 
$5 \mathrm{~mm}$ de profundidade), intestinal e de trato urinário (ambas quando atingiam camadas musculares).

Utilizando a classificação histológica da endometriose (Abrão et al., 2003) que subdivide a doença em quatro apresentações histológicas de acordo com sua maior ou menor semelhança com o endométrio tópico (estromal, bem-diferenciada, padrão misto de diferenciação e doença indiferenciada) agrupamos as pacientes com endometriose em duas categorias, sem indiferenciação (formas estromal ou bem-diferenciada, $\mathrm{n}=$ 28) e com indiferenciação (formas mista e indiferenciada, $n=44$ ).

Antes da anestesia geral foram colhidos $5 \mathrm{~mL}$ de sangue periférico e também foi anotado o dia do ciclo menstrual em que a paciente se encontrava. Foi realizado o preparo habitual para a videolaparoscopia com punção umbilical e pneumoperitôneo sem instilação de soro fisiológico na cavidade. Após a punção auxiliar foi colhido o fluido peritoneal depositado nos fundos-de-saco anterior e posterior quando estava presente, cujo volume variou entre 2 e $10 \mathrm{~mL}$ O material foi armazenado em tubo seco e encaminhado ao laboratório para ser centrifugado, aliquotado e congelado em freezer à $-20^{\circ} \mathrm{C}$. Depois de estocado, o mesmo somente foi descongelado com a coleta completa de todos os dados, para realização das dosagens das interleucinas 12 e 18. Utilizamos os kits IL-12 (p70) Humana (Human IL-12 p70 Kit, BD Biosciences, San Diego, USA) para a IL-12 e IL18 ELISA (IL-18 ELISA, IBL, Hamburg, Alemanha). Os limites de detecção do kit de IL-12 preconizado pelo laboratório foi de $4 \mathrm{pg} / \mathrm{mL}$ e do kit de IL-18 foi de $9,2 \mathrm{pg} / \mathrm{mL}$.

A análise estatística dos dados obtidos foi realizada através da comparação das dosagens das interleucinas 12 e 18, no sangue e no fluido peritoneal, em relação aos diversos parâmetros anteriormente mencionados. As variáveis estudadas tinham comportamento não-paramétrico e foram analisadas através da aplicação do teste de Kruskal-Wallis quando significante, complementou-se com o teste de Dunn para discriminar a(s) diferença(s). Utilizou-se, para tanto, o "software" SPSS versão 10.0. 


\section{RESULTADOS}

Das 105 pacientes submetidas à videolaparoscopia com quadro clínico sugestivo de endometriose diagnosticou-se a doença em 72; foram, portanto, subdivididas em dois grupos: pacientes com endometriose $(n=72)$ e grupo controle $(n=33)$.

A média das dosagens de IL-12, dosada no fluido peritoneal, mostrouse aumentada nas pacientes com endometriose em relação ao grupo controle $(p<0,001)$.As concentrações séricas de IL-12 não apresentaram diferenças estatísticas na avaliação global entre casos e controles, mas houve aumento significativo da mesma na comparação dos estádios mais avançados em relação aos estádios iniciais ( $p=0,007)$. Em relação à dosagem de IL-18 não houve diferença estatística nas amostras sérica ou no fluido peritoneal (tabelas 1 e 2 )

Tabela 1 - Comparação das médias das dosagens das interleucinas 12 e 18 no sangue e no fluido peritoneal entre o grupo controle e o grupo com endometriose.

\begin{tabular}{|c|c|c|c|c|}
\hline & IL 12 & & IL18 & \\
\hline & sangue & Fluido peritoneal & sangue & Fluido peritoneal \\
\hline Controle & $97,13+/-19,02$ & $29,20+/-10,21$ & $62,07+/-8,08$ & $112,51+/-29,24$ \\
\hline EDT & $152,14+/-22,59$ & $82,37+/-16,61$ & $70,52+/-0,00$ & $142,54+/-23,39$ \\
\hline $\mathrm{p}$ & 0,16 & $<0,001^{*}$ & 0,39 & 0,22 \\
\hline
\end{tabular}


Tabela 2 - Comparação das médias das dosagens das interleucinas 12 e 18 sérica e no fluido peritoneal entre o grupo com endometriose subdivididos segundo o estadiamento (pg/mL)

\begin{tabular}{|c|c|c|c|c|c|c|c|c|}
\hline \multirow[t]{3}{*}{ Interleucina } & \multicolumn{4}{|c|}{$\underline{\mathrm{IL}-12}$} & \multicolumn{3}{|c|}{$\underline{\text { IL-18 }}$} & \\
\hline & \multicolumn{2}{|c|}{ estádios I/II } & \multicolumn{2}{|c|}{ estádios III/IV } & \multicolumn{2}{|c|}{ estádios I/II } & \multicolumn{2}{|c|}{ estádios III/IV } \\
\hline & sangue & FP & sangue & FP & sangue & FP & sangue & FP \\
\hline média & 82,04 & 62,54 & 196,74 & 94,98 & 51,28 & 97,21 & 82,77 & 171,38 \\
\hline erro padrãc & 16,63 & 14,13 & 33,91 & 25,61 & 10,56 & 27,21 & 17,49 & 33,65 \\
\hline p-value & $0,007^{*}$ & 0,71 & & & 0,63 & 0,05 & & \\
\hline
\end{tabular}

A análise das dosagens das interleucinas 12 e 18 no sangue e no fluido peritoneal em relação à fase do ciclo de coleta das amostras não apresentou diferença estatisticamente significativa, conforme demonstrado na tabela 3 .

Tabela 3 - Comparação das dosagens das interleucinas 12 e 18 sérica e no fluido peritoneal entre as pacientes com endometriose e o grupo controle nas fases folicular e lútea do ciclo menstrual (pg/mL)

\begin{tabular}{lccccc}
\hline & Controle & & \multicolumn{3}{c}{ ENDOMETRIOSE } \\
\hline & $\underline{\text { sangue }}$ & Fluido peritoneal & $\underline{\text { sangue }}$ & Fluido peritoneal \\
\cline { 6 - 6 } IL12 Fase folicular & $101.98+24.21$ & $36.04+13.2$ & & $125.25+19.46$ & $82.54+16.58$ \\
IL12 Fase lútea & $81.98+22.32$ & $7.83+3.83$ & $152.69+45.98$ & $40.56+14.2$ \\
& $p$ & 0,753 & 0,176 & 0,644 & 0,231 \\
& & & & \\
IL18 Fase folicular & $56.29+7.67$ & $126.62+37.05$ & $57.57+10.17$ & $159.98+29.94$ \\
IL18 Fase lútea & $80.12+23.25$ & $68.38+32.34$ & $56.49+26.09$ & $91.2+33.28$ \\
& $p$ & 0,542 & 0,444 & 0,542 & 0,479 \\
\hline
\end{tabular}

Também foram analisadas as concentrações de interleucinas 12 e 18 sérica e no fluido peritoneal em relação à localização da doença e à 
classificação histológica da endometriose (Abrão et al., 2003). Neste quesito 15 pacientes apresentavam a doença exclusivamente peritoneal, 21 pacientes doença ovariana e 36 pacientes doença profunda, ressaltando que mais de uma forma poderia coexistir na paciente sendo sempre considerada a forma mais grave. Não houve diferença estatisticamente significativa em relação a esses dois parâmetros estudados para nenhuma das interleucinas, conforme demonstrado nas tabelas 4 e 5 .

Tabela 4 - Comparação das dosagens das interleucinas 12 e 18 no sangue e no fluido peritoneal de pacientes com endometriose em relação ao local de doença

\begin{tabular}{|c|c|c|c|c|c|c|c|c|}
\hline \multirow{2}{*}{\multicolumn{2}{|c|}{ Variável }} & \multicolumn{2}{|c|}{ Ovário $(n=21)$} & \multicolumn{2}{|c|}{ Peritônio (n=15) } & \multicolumn{2}{|c|}{ Profunda $(n=36)$} & \multirow[b]{2}{*}{$p$} \\
\hline & & Média & $\begin{array}{c}\text { Erro } \\
\text { padrão }\end{array}$ & Média & $\begin{array}{c}\text { Erro } \\
\text { padrão }\end{array}$ & Média & $\begin{array}{c}\text { Erro } \\
\text { padrão }\end{array}$ & \\
\hline \multirow[t]{2}{*}{ IL - 12} & $\mathrm{sg}$ & 146,43 & 43,86 & 96,86 & 28,00 & 178,50 & 35,24 & 0,31 \\
\hline & FP & 53,02 & 15,20 & 71,59 & 19,32 & 103,98 & 30,83 & 0,62 \\
\hline \multirow[t]{2}{*}{ IL - 18} & $\mathrm{sg}$ & 68,91 & 17,32 & 103,56 & 38,08 & 57,70 & 13,43 & 0,42 \\
\hline & FP & 142,26 & 56,52 & 109,89 & 37,86 & 156,30 & 29,95 & 0,31 \\
\hline
\end{tabular}

Tabela 5 - Comparação das dosagens das interleucinas 12 e 18 no sangue e no fluido peritoneal de pacientes com endometriose em relação à classificação histológica

\begin{tabular}{|c|c|c|c|c|c|c|c|c|c|}
\hline \multirow[b]{2}{*}{ Categoria Histológica } & \multicolumn{4}{|c|}{$\underline{\text { L12 Fluido peritoneal } ~ L L 12 \text { Sérica }}$} & \multicolumn{5}{|c|}{$\underline{\text { L18 Fluido peritoneal } \amalg \text { L18 Sérica }}$} \\
\hline & $n$ & média & $\begin{array}{c}\text { erro } \\
\text { padrão }\end{array}$ & média & $\begin{array}{c}\text { erro } \\
\text { padrão }\end{array}$ & média & $\begin{array}{c}\text { erro } \\
\text { padrão }\end{array}$ & média & $\begin{array}{c}\text { erro } \\
\text { padrão }\end{array}$ \\
\hline Sem indiferenciação & 28 & 63,21 & 13,77 & 104,04 & 21,01 & 123,39 & 29,30 & 80,17 & 22,89 \\
\hline Com indiferenciação & 44 & 94,56 & 25,70 & 182,74 & 33,86 & 154,72 & 33,55 & 64,39 & 12,16 \\
\hline$p$ & & 0,9120 & & 0,1149 & & 0,8524 & & 0,7859 & \\
\hline
\end{tabular}




\section{DISCUSSÃO}

O presente estudo avaliou o comportamento das interleucinas 12 e 18 no sangue e no fluido peritoneal em um grupo controle composto por 33 pacientes com quadro clínico sugestivo e ausência comprovada de endometriose e em 72 pacientes com endometriose com diferentes estádios, locais de doença, subtipos histológicos e coletas nas duas fases do ciclo menstrual. A análise destes parâmetros correlacionados às dosagens das referidas interleucinas representa uma nova proposta no entendimento da fisiopatologia da endometriose. Sabidamente, a IL-12 e a IL-18 participam da resposta imunológica, em especial da reposta Th1. Reconhecemos ser este um dos prováveis mecanismos envolvidos na etiopatogenia da doença, daí a importância do conhecimento mais profundo acerca do comportamento das duas citocinas estudadas.

A fase do ciclo menstrual pode ser entendida como de relevância para o entendimento do comportamento das interleucinas na endometriose. Entendemos que o refluxo de células endometriais para a cavidade pélvica desencadeie a resposta imunológica e inflamatória agudamente, esperando, portanto, aumento das dosagens de citocinas inflamatórias nessas circunstâncias. Nossos resultados, no entanto, não mostraram diferenças significativas nas comparações das dosagens de IL-12 e IL-18 nas fases folicular e lútea do ciclo menstrual independente de a paciente ter ou não endometriose. Outros trabalhos da literatura também não haviam demonstrado tal diferença (Gazvani et al., 2001) e alguns mostraram diferenças com elevação das dosagens peritoneais de IL-18 na fase lútea em comparação com a fase secretória em pacientes com endometriose (Arici et al., 2003).

A análise das dosagens de IL-12 mostrou que, no fluido peritoneal, a mesma se encontrava significativamente aumentada de pacientes com endometriose em relação ao grupo controle; no sangue esta citocina estava 
mais elevada em pacientes com endometriose avançada do que nas pacientes com doença inicial. Portanto, quando subdivididas segundo o estadiamento, as pacientes com endometriose avançada apresentavam dosagens séricas de IL-12 significativamente maiores que na endometriose inicial. Outros estudos, com metodologia semelhante, encontraram resultados diferentes, apontando não haver diferenças nas dosagens de IL12, quer tenha sido feita análise no sangue ou fluido peritoneal (Mazzeo et al., 1998; Zeyneloglu et al., 1998; Gazvani et al., 2001). Nossos resultados podem refletir que nas pacientes com a doença há realmente uma ativação imunológica visando à via de resposta celular inicial em combate ao antígeno representado pelo tecido endometrial, desencadeada rapidamente quando o mesmo chega à cavidade pélvica. Como a diferença estatística marcante também foi encontrada entre as pacientes do grupo controle e os estádios I e II da endometriose, é possível desenhar um raciocínio que a chegada de células endometriais à cavidade pélvica desencadeia, de imediato, a resposta imune Th1.

A interleucina 18 não mostrou diferenças estatisticamente significativas quando realizada a avaliação segundo o estadiamento, mas notamos uma tendência de elevação das dosagens de IL-18 no fluido peritoneal em estádios avançados da doença $(p=0,08)$. Três trabalhos foram publicados sobre o comportamento da IL-18 nas mulheres com endometriose. Seus resultados são conflitantes de modo que até o momento não há consenso na literatura sobre a relação da IL-18 na doença, o que nos motivou a averiguar tal situação em pacientes de nosso meio (Arici et al., 2003; Oku et al., 2004; Zhang et al., 2004). Nosso trabalho não encontrou diferenças estatisticamente significantes nas dosagens sérica ou peritoneal da IL-18 na comparação de pacientes com endometriose e grupo controle, mas uma tendência ao aumento de IL-18 peritoneal nos estádios avançados da doença.

A via comumente envolvida na secreção da IL-12 passa, inicialmente, pela secreção de IL-18 que, como vimos, é cofator importante para sua liberação. Nossos resultados mostraram, na avaliação das dosagens da IL- 
18 houve tendência ao aumento da mesma em estádios avançados da doença, não tendo diferenças nos estádios iniciais, onde foi encontrada a diferença anteriormente mencionada em relação à IL-12 peritoneal. Como interpretar tal discordância entre as dosagens peritoneais de IL-12 e IL-18 se assumíssemos ser um processo encadeado?

Deparamo-nos, aqui, com um conceito recente, de que nem sempre a produção de IL-12 seja dependente do estímulo da IL-18. Já se acredita que exista uma outra via de produção de IL-12 que independe do estímulo de IL18 (Morita et al., 2005). Esta, talvez, seja a via predominantemente envolvida na endometriose, explicando o porquê do aumento das dosagens de IL-12 sem modificação significativa das dosagens de IL-18.

A análise do local da doença foi realizada respeitando o critério de gravidade onde a doença profunda é considerada a mais agressiva e a forma peritoneal a mais branda. Inicialmente avaliamos se as interleucinas 12 e 18, tanto no sangue quanto no fluido peritoneal, sofriam alguma alteração na presença isolada da doença peritoneal, mas não encontramos diferenças significativas. Sendo assim, aplicamos o mesmo raciocínio para avaliar a doença profunda isoladamente e também não encontramos diferenças estatisticamente significativas.

Em relação à classificação histológica (Abrão etal., 2003) útil na possibilidade de predizer o padrão de comportamento da doença, não encontramos diferenças estatisticamente significativas. Houve, no entanto, uma tendência a maiores dosagens de IL-12 sérica nas pacientes com formas mais indiferenciadas da doença. Novamente ressaltamos a proposta mais recente da via independente de produção da IL-12. Provavelmente na doença mais agressiva e indiferenciada possamos assumir que a ativação imunológica seja mais intensa já desde o início do processo; sendo assim acreditamos que a elevação da IL-12 nesta forma mais agressiva pode demonstrar esse recrutamento do sistema imune tentando controlar o avanço da mesma.

Entendemos, também, pelas diferenças de comportamento apresentadas em relação às dosagens de IL-12 e IL-18 que na endometriose 
a via alternativa de secreção de IL-12 independente de IL-18 possa estar fortemente ativada.

Nenhum outro trabalho analisado fez estudo semelhante, de modo que apresentamos resultados que podem contribuir no entendimento da fisiopatologia da endometriose e auxiliar no desenvolvimento de novas técnicas diagnósticas e terapêuticas. Futuros estudos se fazem necessários para que consigamos compreender, de modo definitivo, o papel imunológico, histológico e outros diferentes parâmetros envolvidos nesta complexa entidade globalmente conhecida como endometriose.

Agradecimentos: FAPESP (Fundação de Amparo à Pesquisa do Estado de São Paulo) pelo apoio financeiro.

\section{REFERÊNCIAS BIBLIOGRÁFICAS}

1. D'Hooghe TM, Debrock S, Meuleman C, Hill JA, Mwenda JM. Future directions in endometriosis research. Obstet Gynecol Clin North Am 2003; 30: 221-44.

2. Missmer SA, Cramer DW.The epidemiology of endometriosis. Obstet Gynecol Clin North Am 2003; 30: 1-19.

3. Berkkanoglu M, Arici A. Immunology and endometriosis. AJRI 2003; 50: 48-59.

4. Harada T, Iwabe T, Terakawa, N. Role of cytokines in endometriosis. Fertil Steril 2001; 76(1): 1-10.

5. Dias JA Jr, de Oliveira RM, Abrao MS. Antinuclear antibodies and endometriosis. Int J Gynaecol Obstet 2006; 93(3): 262-3.

6. Pasoto SG, Abrao MS, Viana VS, Bueno C, Leon EP, Bonfa E. Endometriosis and systemic lupus erythematosus: a comparative evaluation of clinical manifestations and serological autoimmune phenomena. Am J Reprod Immunol 2005; 53(2): 85-93. 
7. Podgaec S, Abrão MS, Dias Jr JÁ, Rizzo LV, Oliveira RM, Baracat EC. Endometriosis: an inflamatory disease with a Th2 immune response component. Human Reprod 2007; in press.

8. D’Andrea A, Rengaraju M, Valiante NM, Chehimi J, Kubin M, Aste M, Chan S, Kobayashi M, Young, D, Nickbarg E, Chizzonite R, Wolf SF, Trinchieri, G. Production of Natural Killer Cell Stimulatory Factor (Interleukin 12 ) by Peripheral Blood Mononuclear Cells. J Exp Med 1992; 176: 1387-98.

9. Gazvani R, Bates M, Gillian V, Christmas S, Lewis-Jones I, Kingsland C. Concentration of Interleukin-12 in the peritoneal fluid is not influenced by the presence of endometriosis, its stage or the phase of the menstrual cycle. Acta Obstet Gynecol Scand 2001; 80: 175-8.

10. Gallinelli A, Chiossi G, Giannella L, Marsella T, Genazzani AD, Volpe A. Different concentrations of interleukins in the peritoneal fluid of women with endometriosis: relationships with lymphocyte subsets. Gynecol Endocrinol 2004; 18: 144-51.

11. Zhang X, Lin J, Qian Y, Deng L. Decreased levels of interleukin-18 in peritoneal fluid but not in serum of patients with endometriosis. Fertil Steril 2004; 81 (5): 1229-34.

12. Chaouat G, Zourbas S, Ostojic S, Lappree-Delage G, Dubanachet S, Ledee N. A brief review of some of the cytokines expressed at the materno-fetal interface which might challenge the classical Th1/Th2 dichotomy. J Reprod Immunol 2002; 53: 241-56.

13. Lédée-Bataille $N$, Dubanchet $S$, Coulomb-L'hermine $A$, DurandGasselin I, Frydman R, Chaouat G. A new role for natural killer cells, interleukin- (IL)12 and IL-18 in repeated implantation failure after in vitro fertilization. Fertil Steril 2004; 81(1): 59-65.

14. Gracie JA, Robertson SE, McInnes IB. Interleukin-18. J Leukocit Biol 2003; 73: 213-24.

15. Arici A, Matalliotakis I, Goumenou A, Koumantakis G, Vassiliadis S, Selam B, Mahutte NG. Increased levels of interleukin-15 in the 
peritoneal fluid of women wiyh endometriosis: inverse correlation with stage and depth of invasion. Hum. Reprod. 2003; 18 (2): 429-32

16. Abrao MS, Neme RM, Carvalho FM, Aldrighi JM, Pinotti JA. Histological classification of endometriosis as a predictor of response to treatment. Int J Gynaecol Obstet 2003; 82 (1): 31-40.

17. Mazzeo D, Viganò P, Di Blasio AM, Sinigaglia F, Vignali M, PaninaBordignon P. Interleukin 12 and its free p40 subunit regulate immune recognition of endometrial cells: ptential role in endometriosis. $\mathrm{J}$ Clin Endocrinol Metab 1998; 83 (3): 911-6.

18. Moriya Y, Gupta R, Seidl KM, McDonagh KT, Fox DA. Cytokine production by dendritic cells genetically engineered to Express IL-4: induction of Th2 responses and differential regulation of IL-12 and IL23 synthesis. J Gene Med 2005; 7: 869-77.

19. Zeyneloglu HB, Sentruk LM, Seli E. The peritoneal fluid levels of interleukin-12 in women with endometriosis. Am J Reprod Immunol 1998; 39(2): 152-6.

20. Oku H, Kashiwamura SI, Adachi S, Kubota A, Okamura H, Koyama K. Role of IL-18 in pathogenesis of endometriosis. Hum Reprod 2004: 19(3): 709-14.

21. The American Society for Reproductive Medicine . Revised American Society for Reproductive Medicine Endometriosis Classification:1996. Fertil Steril 1997; 67:817-21. 
REFERÊNCIAS BIBLIOGRÁFICAS 


\section{$\underline{\text { Referências Bibliográficas }}$}

1. Abbas AK, Kenneth MM, Sher A. Functional diversity of helper $T$ lymphocytes. Nature 1996; 383: 787-93.

2. Abrao MS, Neme RM, Carvalho FM, Aldrighi JM, Pinotti JA. Histological classification of endometriosis as a predictor of response to treatment. Int J Gynaecol Obstet 2003; 82 : 31-40.

3. Abrao MS, Podgaec S, Dias JA Jr, Averbach M, Garry R, Ferraz Silva LF, Carvalho FM. Deeply infiltrating endometriosis affecting the rectum and lymph nodes. Fertil Steril $2006 ; 27$;

4. Arici A, Matalliotakis I, Goumenou A, Koumantakis G, Vassiliadis S, Selam B, Mahutte NG. Increased levels of interleukin-15 in the peritoneal fluid of women wiyh endometriosis: inverse correlation with stage and depth of invasion. Hum. Reprod. 2003; $18: 429-32$

5. Arici A, Matalliotakis I, Goumenou A, Koumantakis G, Vassiliadis S, Selam B, Mahutte NG. Altered expression of interleukin-18 in the peritoneal fluid of women with endometriosis. Fertil Steril 2003; 80: 889-94.

6. Badawy SZ, Cuenca V, Stitzel A, Tice D. Imune rosettes of T and B lymphocytes in infertile women with endometriosis. J Reprod Med 1987; 32: 194-7.

7. Badawy SZ, Cuenca V, Kaufman L, Stitzel A, Thompson M. The regulation of immunoglobulin production by $B$ cells in patients with endometriosis. Fertil Steril 1989; 51: 770-3.

8. Barcz E, Kaminski P, Marianowski L. Role of cytokines in pathogenesis of endometriosis. Med Sci Monit 2000; 6: 1042-6.

9. Belaisch J, Allart JP. Endometriosis and surviving adolescence. Gynecol Obstet Fertil 2006; 34: 242-7. 
10. Benjamini E, Coico R, Sunshine G. Ativação e função dos linfócitos T e B. In: Imunologia, $4^{\mathrm{a}} \mathrm{ed}$. Rio de Janeiro: Guanabara Koogan; 2002, pp 11-25.

11. Berkkanoglu M, Arici A. Immunology and endometriosis. AJRI 2003; 50: 48-59.

12. Buyalos RP, Funari VA, Azzizz R. Elevated interleukin-6 levels in peritoneal fluid of patients with pelvic endometriosis.Fertil Steril 1992; 53: 302-6.

13. Chaouat G, Zourbas S, Ostojic S, Lappree-Delage G, Dubanachet S, Ledee N. A brief review of some of the cytokines expressed at the materno-fetal interface which might challenge the classical Th1/Th2 dichotomy. J Reprod Immunol 2002; 53: 241-56.

14.D'Andrea A, Rengaraju M, Valiante NM, Chehimi J, Kubin M, Aste M, Chan S, Kobayashi M, Young, D, Nickbarg E, Chizzonite R, Wolf SF, Trinchieri, G. Production of Natural Killer Cell Stimulatory Factor (Interleukin 12 ) by Peripheral Blood Mononuclear Cells. J Exp Med 1992; 176: 1387-98.

15. de Sa Rosa e Silva AC, Rosa e Silva JC, Nogueira AA, Petta CA, Abrao MS, Ferriani RA. The levonorgestrel-releasing intrauterine device reduces CA-125 serum levels in patients with endometriosis. Fertil Steril 2006; 86:742-4.

16. D'Hooghe TM, Xiao L, Hill JA. Cytokine profiles in autologous peritoneal fluid and peripheral blood of women with deep and superficial endometriosis. Arch Gynecol Obstet 2001; 265: 40-4.

17. D'Hooghe TM, Debrock S, Meuleman C, Hill JA, Mwenda JM. Future directions in endometriosis research. Obstet Gynecol Clin North Am 2003; 30: 221-44.

18.Dmowski WP, Steele RW, Baker GF. Deficient cellular immunity in endometriosis. Am J Obstet Gynecol 1981; 141: 377-83.

19.Dmowski WP, Lesniewicz R, Rana N, Pepping P, Nowisalehi M. Changing trends in the diagnosis of endometriosis: a comparative 
study of women with pelvic endometriosis presenting with chronic pelvic pain or infertility. Fertil Steril 1997; 67: 238-43.

20. Esfandiari E, Mclnnes IB, Lindop G, Huang FP, Field M, Komai-Koma M, Xei X, Liew FY. A proinflammatory role of IL-18 in the development of spontaneous autoimmune disease. J Immunol 2001; 167: 5338-47.

21. Eskenazi B, Warner M L. Epidemiology of endometriosis. Obstet Gynecol Clin North Am 1997; 24: 235-58.

22. Gallinelli A, Chiossi G, Giannella L, Marsella T, Genazzani AD, Volpe A. Different concentrations of interleukins in the peritoneal fluid of women with endometriosis: relationships with lymphocyte subsets. Gynecol Endocrinol 2004; 18: 144-51.

23. Gazvani R, Bates M, Gillian V, Christmas S, Lewis-Jones I, Kingsland C. Concentration of Interleukin-12 in the peritoneal fluid is not influenced by the presence of endometriosis, its stage or the phase of the menstrual cycle. Acta Obstet Gynecol Scand 2001; 80: 175-8.

24. Gazvani R, Smith L, Fowler P. Effect of interleukin-8, anti-IL-8, and IL12 on endometrial cell survival in combined endometrial gland and stromal cell cultures derived from women with and without endometriosis. Fertil Steril 2002; 77 : 62-7.

25. Gleicher N, El-Roeiy A, Confino E, Freiberg, J. Is endometriosis an autoimmune disease? Obstet Gynecol 1987; 70:115-22.

26. Giudice LC, Kao LC. Endometriosis. Lancet 2004; 364: 1789-99.

27. Glitz CL. Concentração sérica e peritoneal de interleucina -18 (IL-18) em mulheres inférteis com endometriose mínima ou leve.[Dissertação]. Porto Alegre: Faculdade de Medicina, Universidade Federal do Rio Grande do Sul; 2006.

28. Gracie JA, Robertson SE, Mclnnes IB. Interleukin-18. J Leukocit Biol 2003; 73: 213-24.

29. Halme J, Becker S, Wing R. Accentuated cyclic activation of peritoneal macrophages in patients with endometriosis. Am J Obstet Gynecol 1984; 148: 85-90. 
30. Hansen KA, Eyster KM. A review of current management of endometriosis in 2006: an evidence-based approach. S D Med 2006; $59: 153-9$.

31. Harada T, Iwabe T, Terakawa, N. Role of cytokines in endometriosis. Fertil Steril 2001; 76: 1-10.

32. Hsu CC, Yang BC, Wu MH, Huang KE. Enhanced interleukin-4 expression in patients with endometriosis.Fertil Steril 1997; 67: 105964.

33. Izzo CR, Izzo VM, Abrão MS. Infertilidade e endometriose: causa ou conseqüência? In Abrão MS, editor. Endometriose, uma visão contemporânea São Paulo: Revinter ;2000, pp.27-34.

34. Khan KN, Masuzaki H, Fujishita A, Hamasaki T, Kitajima M, Hasuo A, Miyamura $Y$, Ishimaru T. Association of interleukin-6 and estradiol with hepatocyte growth factor in peritoneal fluid of women with endometriosis. Acta Obstet Gynecol Scand 2002; 81: 764-71.

35. Khan KN, Masuzaki H, Fujishita A, Kitajima M, Hiraki K, Muira S, Sekine I, Ishimaru T. Peritoneal fluid and serum levels of hepatocyte growth factor may predict the activity of endometriosis. Acta Obstet Gynecol Scand 2006; 85 : 458-66.

36. Kobayashi M, Fitz L, Ryan M, Hewick RM, Clark SC, Chan S, Loudon $R$, Sherman F, Perussia B, Trinchieri G. Identification and purification of natural killer cell stimulatory factor (NKSF), a cytokine with multiple biologic effects on human lymphocytes. J Exp Med 1989; 170: 827-45.

37. Koninckx PR, Barlow D, Kennedy S. Implantation versus Infiltration: The Sampson versus the Endometriotic Disease Theory. Gynecol Obstet Invest 1999; 47(suppl 1): 3-10.

38. Lebovic DI, Mueller MD, Taylor RN. Immunobiology of endometriosis. Fertil Steril 2001; $75: 1-10$.

39. Lédée-Bataille $N$, Dubanchet $S$, Coulomb-L'hermine $A$, DurandGasselin I, Frydman R, Chaouat G. A new role for natural killer cells, interleukin- (IL)12 and IL-18 in repeated implantation failure after in vitro fertilization. Fertil Steril 2004; 81: 59-65. 
40. Lédée-Bataille N, Bonnet-Chea K, Hosny G, Dubanchet S, Frydman $\mathrm{R}$, Chaouat $\mathrm{G}$. Role of endometrial tripod interleukin-18, -15 , and -12 in inadequate uterine receptivity in patients with a history of repeated in vitro fertilization-embryo transfer failure. Fertil Steril 2005; 83: 598605.

41. Lewkowich IP, Hayglass KT.Endogenous IFN-gama and IL-18 production directly limit induction of type 2 immunity in vivo. Eur $\mathrm{J}$ Immunol 2002; 32: 3256-45.

42. Luo Q, Ning W, Wu Y, Zhu X, Jin F, Sheng J. Altered expression of interleukin-18 in the ectopic and eutopic endometrium of women with endometriosis. J Reprod Immunol 2006; 72: 108-17.

43. Matorras R, Rodíquez F, Pijoan JI, Ramón O, Terán GG, RodríguezEsacudero F. Epidemiology of endometriosis in infertile women. Fértil Steril 1995, 63: 34-8.

44. Mazzeo D, Viganò P, Di Blasio AM, Sinigaglia F, Vignali M, PaninaBordignon $\mathrm{P}$. Interleukin 12 and its free p40 subunit regulate immune recognition of endometrial cells: ptential role in endometriosis. J Clin Endocrinol Metab 1998; 83: 911-6.

45. Missmer SA, Cramer DW. The epidemiology of endometriosis.Obstet Gynecol Clin N Am 2003; 30:1-19.

46. Moriya Y, Gupta R, Seidl KM, McDonagh KT, Fox DA. Cytokine production by dendritic cells genetically engineered to Express IL-4: induction of Th2 responses and differential regulation of IL-12 and IL23 synthesis. J Gene Med 2005; 7: 869-77.

47. Nakanishi K, Yoshimoto T, Tsutsui H, Okamura H. Interleukin-18 is a unique cytokine that stimulates both Th1 and Th2 responses depending on its cytokine milieu. Cytokine Growth Factor Rev 2001; 12: 53-72.

48. Neme RM, Abrão MS. Fisiopatologia e quadro clínico da endometriose. In: Abrão MS, editor. Endometriose, uma visão contemporânea São Paulo: Revinter; 2000, pp. 55-65. 
49. Nisolle M, Donnez J. Peritoneal endometriosis, ovarian endometriosis and adenomyotic nodules of the rectovaginal septum are three different entities. Fertil Steril 1997; 68: 585-96.

50. Nothnick WB. Treating endometriosis as na autoimmune disease. Fertil Steril 2001; 76: 223-31.

51. Oosterlynck DJ, Cornillie FJ, Waer M, Vandeputte M, Koninckx PR. Women with endometriosis show a defect in natural killer activity resulting in a decreased cytotoxicity to autologous endometrium. Fertil Steril 1991; 56:45-51.

52. Oku H, Kashiwamura SI, Adachi S, Kubota A, Okamura H, Koyama K. Role of IL-18 in pathogenesis of endometriosis. Hum Reprod 2004: 19: 709-14.

53. Park CC, Morel JC, Amim MA, Connors MA, Harlow LA, Kock AE. Evidence of IL-18 as a novel angiogenic mediator. J Immunol 2001; 167: 1644-53.

54. Pasoto SG, Abrao MS, Viana VS, Bueno C, Leon EP, Bonfa E. Endometriosis and systemic lupus erythematosus: a comparative evaluation of clinical manifestations and serological autoimmune phenomena. Am J Reprod Immunol 2005; 53: 85-93.

55. Petta CA, Ferriani RA, Abrao MS, Hassan D, Rosa e Silva JC, Podgaec S, Bahamondes L. Randomized clinical trial of a levonorgestrel-releasing intrauterine system and a depot GnRH analogue for the treatment of chronic pelvic pain in women with endometriosis. Hum Reprod 2005; 20: 1993-8.

56. Pizzo A, Salmeri FM, Ardita FV, Sofo V, Tripepi M, Marsico S. Behaviour of Cytokine Levels in Serum and Peritoneal Fluid of Women with Endometriosis. Gynecol Obstet Invest 2002; 54: 82-7.

57.Podgaec S, Abrao MS. The role of immunology in the etiopathogenesis, diagnosis and treatment of endometriosis. Einstein 2005; 3: 203-6. 
58.Podgaec S, Abrão MS, Dias Jr JÁ, Rizzo LV, Oliveira RM, Baracat EC. Endometriosis: an inflamatory disease with a Th2 immune response component. Human Reprod 2007; in press.

59. Punnonen J, Teisala K, Ranta H, Bennett B, Punnonen R. Increased levels of interleukin- 6 and interleukin-10 in the peritoneal fluid of patients with endometriosis. Am J Obstet Gynecol 1996; 174: 1522-6.

60. Roitt I, Brostoff J, Male D. Imunologia 6ª ed. São Paulo: Manole; 2003.

61.Sampson JA. Peritoneal endometriosis due to the menstrual dissemination of endometrial tissue into the peritoneal cavity. $A m \mathrm{~J}$ Obstet Gynecol 1927; 14: 422-69.

62. Somigliana E, Viganò P, Rossi G, Carinelli S, Vignali M, PaninaBordignon P. Endometrial ability to implant in ectopic sites can be prevented by interleukin-12 in a murine model of endometriosis. Hum Reprod 1999; 14 : 2944-50.

63. Somigliana E, Viganò $P$, Filardo $P$, Candiani M, Vignali $M$, PaninaBordignon $P$. Use of knockout transgenic mice in the study of endometriosis: insights from mice lacking beta2-microglobulin and interleukin-12p40. Fertil Steril 2001; 75 : 203-6.b

64. Syrop $\mathrm{CH}$, Halme J. Cyclic changes of peritoneal fluid parameters in normal and infertile patients. Obstet Gynecol 1987; 69: 416-8.

65. Syrop $\mathrm{CH}$, Halme J. Peritoneal fluid environment and infertility. Fertil Steril 1987; 48: 1-9.

66. Ulukus M, Arici A. Immunology of endometriosis. Minerva Ginecol 2005; $57:$ 237-48.

67. Weed JC, Arquembourg PC. Endometriosis: can it produce an autoimmune response resulting in infertility? Clin Obstet Gynecol 1980; $23: 885-93$.

68. Wilson R, Jenkins C, Miller H, Mclnnes IB, Moore J, McLean MA, Walker JJ. Abnormal cytokine levels in non-pregnant women with a history of recurrent miscarriage. Eur J Obstet Gynecol Reprod Biol 2004; 115: 51-4. 
69. Witz CA. Pathogenesis of Endometriosis. Gynecol Obstet Invest 2002; 53(suppl 1): 52-62.

70. Wu MY, Ho HN. The Role of Cytokines in Endometriosis. AJRI 2003; 49: 285-96.

71. Yoshino O, Osuga Y, Koga K, Tsutsumi O, Yano T, Fujii T. Evidence for the expression of interleukin(IL)-18, IL-18 receptor and IL-18 binding protein in the human endometrium. Mol Hum Reprod 2001; 7: 649-54.

72. Revised American Fertility Society Classification of Endometriosis: 1985. Fertil Steril 1985; $43: 351-2$.

73. The American Society for Reproductive Medicine . Revised American Society for Reproductive Medicine Endometriosis Classification:1996. Fertil Steril 1997; 67:817-21.

74.Zhang X, Lin J, Qian Y, Deng L. Decreased levels of interleukin-18 in peritoneal fluid but not in serum of patients with endometriosis. Fertil Steril 2004; 81 : 1229-34.

75.Zeyneloglu HB, Sentruk LM, Seli E. The peritoneal fluid levels of interleukin-12 in women with endometriosis. Am J Reprod Immunol 1998; 39: 152-6. 